Florida International University

FIU Digital Commons

FIU Electronic Theses and Dissertations

University Graduate School

$11-9-2011$

\title{
Heart Valve Tissue Engineering: A Study of Time Varying Effects and Sample Geometry
}

Manuel Salinas

Florida International University, msalinas@nova.edu

Follow this and additional works at: https://digitalcommons.fiu.edu/etd

\section{Recommended Citation}

Salinas, Manuel, "Heart Valve Tissue Engineering: A Study of Time Varying Effects and Sample Geometry" (2011). FIU Electronic Theses and Dissertations. 522.

https://digitalcommons.fiu.edu/etd/522

This work is brought to you for free and open access by the University Graduate School at FIU Digital Commons. It has been accepted for inclusion in FIU Electronic Theses and Dissertations by an authorized administrator of FIU Digital Commons. For more information, please contact dcc@fiu.edu. 


\section{FLORIDA INTERNATIONAL UNIVERSITY}

Miami, Florida

HEART VALVE TISSUE ENGINEERING: A STUDY OF TIME VARYING EFFECTS AND SAMPLE GEOMETRY

A thesis submitted in partial fulfillment of

the requirements for the degree of

MASTER OF SCIENCE

in

BIOMEDICAL ENGINEERING

by

Manuel Salinas 
To: Dean Amir Mirmiran

College of Engineering and computing

This thesis, written by Manuel Salinas, and entitled Heart Valve Tissue Engineering: A Study of Time Varying Effects and Sample Geometry, having been approved in respect to style and intellectual content, is referred to you for judgment.

We have read this thesis and recommend that it be approved.

Girma Bitsuamlak

Yen-Chi Huang

Sharan Ramaswamy, Major Professor

Date of Defense: November 09, 2011

The thesis of Manuel Salinas is approved.

Dean Amir Mirmiran Dean of the College of Engineering and computing

Dean Lakshmi N. Reddi University Graduate School

Florida International University, 2011 


\section{DEDICATION}

I dedicate this thesis to my family for all their support at all times on and off campus. Without their help this report would not have been possible. 


\section{ACKNOWLEDGMENTS}

I wish to thank my advisor Dr. Sharan Ramaswamy for his continuous guidance. Also, my committee members Dr. Yen-Chi Huang and Dr. Girma Bitsuamlak for directing my research in the right direction, the MBRS-RISE program for its generous support and the BME faculty and Staff. 
ABSTRACT OF THE THESIS

HEART VALVE TISSUE ENGINEERING: A STUDY OF TIME VARYING EFFECTS

AND SAMPLE GEOMETRY

by

Manuel Salinas

Florida International University, 2011

Miami, Florida

\section{Professor Sharan Ramaswamy, Major Professor}

In heart valve tissue engineering (HVTE), it is well established that mechanical stimuli improve tissue formation and cell growth. Previous experiments have shown that combined flexure and flow increases tissue formation in PLA/PGA scaffolds seeded with bone marrow derived stem cells (BMSCs). In addition, computational fluid dynamic (CFD) studies have shown that sample bending significantly affects the flow physics. The intend of this study was to observe and compare the flow physics between steady state and pulsatile cases through computational modeling and in-vitro experiments. A u-shaped custom made bioreactor capable of producing flow stretch and flexure was used. CFD simulations were performed through Ansys CFX (Ansys, Pittsburgh, PA) for both steady and pulsatile flow. The results have shown that OSS can be maximized by inducing pulsatile flow over straight scaffolds. Evidence suggests that OSS promotes BMSCs tissue formation. 


\section{TABLE OF CONTENTS}

CHAPTER

PAGE

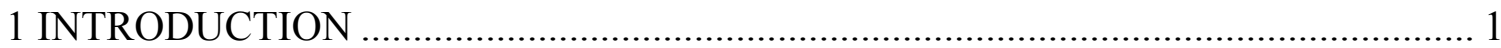

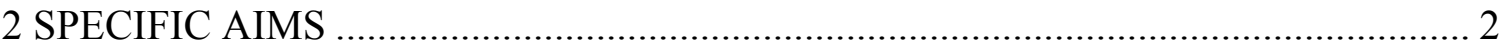

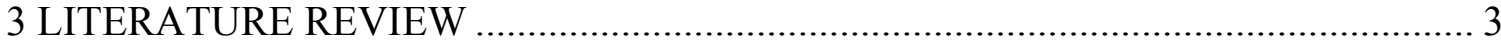

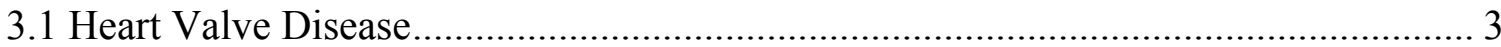

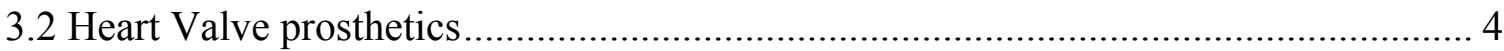

3.3 Computational Fluid Dynamic in Heart Valves........................................................... 6

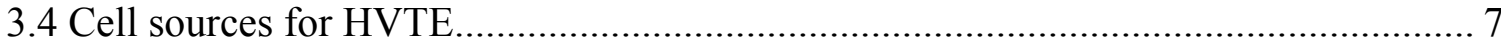

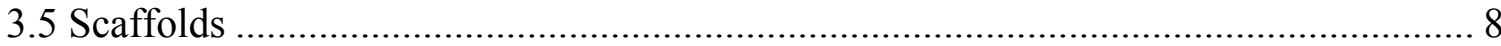

3.6 Mechanical Conditioning .................................................................................. 9

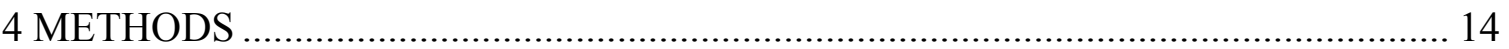

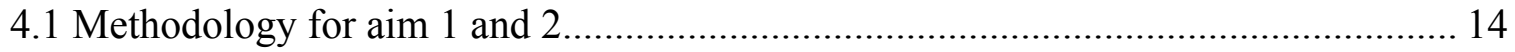

4.1.1 Initial Geometry and meshing for all simulations/fluid properties.................... 14

4.1.2 Displacement and Non-linear constant calculations........................................ 16

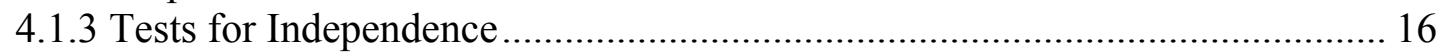

4.1.4 Methodology for aim 1- Steady state simulations ............................................ 17

4.1.5 Methodology for aim 2- Static pulsatile simulations....................................... 17

4.2 Methodology for aim 3- Cell Culture experiments................................................. 20

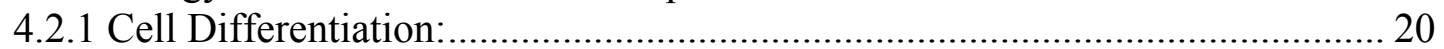

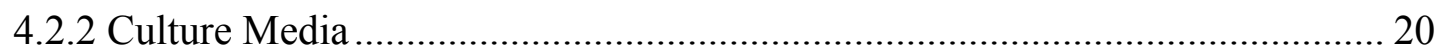

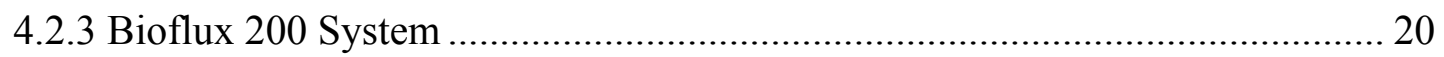

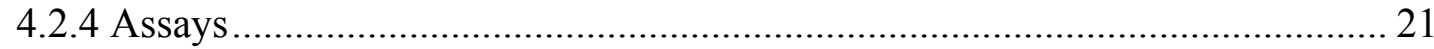

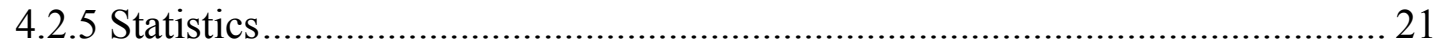

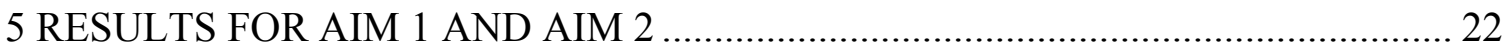

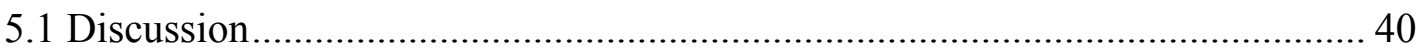

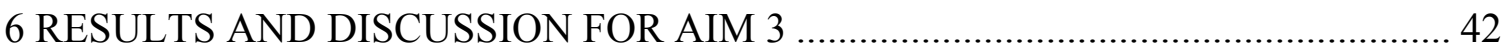

7 CONCLUSION

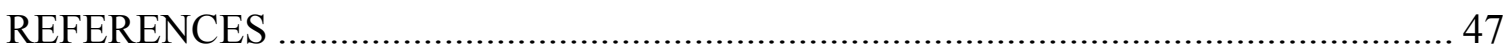




\section{LIST OF FIGURES}

Figure 1. Mechanical and Biological Heart valves.

Figure 2. Tissue Engineering Approach.

Figure 3. Computational fluid dynamic simulations on native heart valve (a) and rectangular (b) geometries.

Figure 4. Custom made mechanical conditioning bioreactor for HVTE studies.

Figure 5. (A) FSF bioreactor set up. (B) Peristaltic pump used to induce flow through the FSF bioreactor. (C) Single FSF bioreactor chamber. (D) Bioreactor fluid domain showing the position of the three rectangular specimens.

Figure 6. (A) Tetrahedral mesh with $3.1 \times 10^{6}$ elements and $5.5 \times 10^{5}$ nodes.

Figure 7. A) Flow rate waveform adjusted from $1.2 \mathrm{sec}$ to $1 \mathrm{sec}$. B) Velocity waveform with a velocity average of $0.199386 \mathrm{~cm} / \mathrm{s}$.

Figure 8. Time averaged wall shear stress distributions in the inner $(n=3)$ and outer $(n=3)$ walls of the specimen for three geometry positions under pulsatile and quasi-static conditions.

Figure 9. Bar chart showing time averaged shear stress.

Figure 10. Inner wall of a straight sample shear stress magnitude with superimposed wall shear vectors.

Figure 11. outer wall of a straight sample shear stress magnitude with superimposed wall shear vectors.

Figure 12. Inner wall of a semibent sample shear stress magnitude with superimposed wall shear vectors.

Figure 13. Outer wall of a semibent sample shear stress magnitude with superimposed wall shear vectors.

Figure 14. Inner wall of a fully-bent sample shear stress magnitude with superimposed wall shear vectors.

Figure 15. Outer wall of a fullybent sample shear stress magnitude with superimposed wall shear vectors. 
Figure 16. Shear stress streamlines on the outer and inner walls of a straight sample under steady $(\mathrm{vel}=0.022 \mathrm{~m} / \mathrm{s})$ and pulsatile conditions.

Figure 17. Axial shear stress (Flow direction) streamlines on the outer and inner walls of a straight sample in steady state cases $(\mathrm{vel}=2.2 \mathrm{~cm} / \mathrm{s})$.

Figure 18. Inner wall of a straight sample with superimposed axial (Flow-direction) shear stress vectors at steady and instantaneous velocities.

Figure 19. Outer wall of a straight sample with superimposed axial (Flow-direction) shear stress vectors at steady and instantaneous velocities.

Figure 20. Inner wall of a straight sample showing axial shear stress magnitude at steady and instantaneous velocities.

Figure 21. Outer wall of a straight sample showing axial shear stress magnitude at steady and instantaneous velocities.

Figure 22. Oscillatory shear index contour for the inner $(n=3)$ and outer walls $(n=3)$. It shows four cases: straight pulsatile, semi-bent pulsatile, fully-bent pulsatile and quasistatic.

Figure 23. Bar chart showing OSI.

Figure 24. Inner wall OSI distribution along the centerline of samples.

Figure 25. Outer wall OSI distribution along the centerline of samples.

Figure 26. (a) Centerline showing the upper and lower chamber of the u-shaped bioreactor (b) Steady state velocity at the upper chamber centerline for three sample configurations.

Figure 27. Velocity along the centerline at $\mathrm{t}=0.1 \mathrm{sec}$ (straight samples).

Figure 28 . Velocity along the centerline at $\mathrm{t}=0.13 \mathrm{sec}$ (straight samples).

Figure 29. Velocity along the centerline at $\mathrm{t}=0.15 \mathrm{sec}$ (straight samples).

Figure 30. Velocity along the centerline at $\mathrm{t}=0.2 \mathrm{sec}$ (straight samples).

Figure 31. Time average vorticity along the centerline of the upper chamber for pulsatile and quasi-static.

Figure 32. Instantaneous vorticity along the centerline of the upper chamber with straight samples and pulsatile flow. 
Figure 33. Bar chart showing the number of cells per day during the steady flow experiment.

Figure 34. Bar chart showing the genes expressed after no flow and steady flow conditions.

Figure 35. Collagen assay results for BMSC-seeded 50:50 PGA/PLLA scaffolds.

Figure 36. A compilation of the temporal evolution of collagen mass production for all groups investigated at the tissue and organ levels. 


\section{INTRODUCTION}

Heart valve disease is a major health care concern around the world. It is estimated that over 290,000 replacements occur annually, and it is expected to triple in the next four decades [1]. Native heart valves (NHVs) are multilayered highly adaptable and highly regulated structures. NHVs open and close nearly three billion times in an average lifespan and their motion depend on the mechanical and hemodynamic forces [2]. Healthy pulmonary heart valves (PHVs) assure one-way blood flow from the right ventricle into the pulmonary artery with minimum regurgitation and negligible obstruction during systole. During diastole, the PHV closes when the pulmonary artery pressure exceeds the ventricular pressure. The closing of the PHVs is aided by flow vortices behind the cusps on the arterial side [2]. Native PHVs are subjected to complex time-varying stresses due to combinations of flow, stretch and flexure (FSF). They are tightly regulated with continuous tissue remodeling activity capable of adapting to different hemodynamic loads [3].

Prosthetic heart valves have shown to provide sufficient functionality; however, mechanical heart valves (MHVs) are prone to hemolysis and possible platelet activation due to abnormal hemodynamics [4]. On the other hand, biological heart valves (BHVs) can fail due to calcification and immune rejection [3,5]. MHVs are widely used among pediatric patients due to the risk of $\mathrm{BHV}$ calcification resulting from elevated calcium concentration found in children [6]. However with MHVs, several revision surgeries are necessary to account for the growth of the child. In addition, immune rejection is still a problem. Ultimately, prosthetic heart valves do not address tissue adaptation, which is 
sorely needed among pediatric patients suffering from severe congenital valve disease/abnormalities.

The objectives of this proposal are to study the effects of two parameters that could potentially augment in vitro engineered heart valve tissue formation. These parameters are linked to the general process of mechanical conditioning which is thought to be important in optimizing tissue formation [7,8]. Specifically, this work examined the

effects of i) sample geometry and ii) pulsatility on fluid-induced stress states and subsequent implications that may have on engineered tissue formation, which are addressed in the following specific aims.

\title{
2 SPECIFIC AIMS
}

\section{Aim 1: Understand the role of specimen geometry in the context of heart valve tissue engineering studies.}

Changes in specimen geometry results in spatially varying flow physics. The intention is to observe the flow physics that occurs during sample flexure. In order to do this, computational fluid dynamics (CFD) simulations were performed as described in the methods section.

\begin{abstract}
Aim 2: Understand the role of pulsatility in the context of heart valve tissue engineering studies.

Pulsatility introduces frequency, waveform, and oscillatory effects. These time varying effects that may be important in the development of tissue engineered heart valve (TEHV) constructs.
\end{abstract}




\section{Aim 3: Co-relate the role of steady and pulsatile flow-induced stress states to engineered tissue formation, specifically collagen and glycosaminoglycan (GAGs) production by bone marrow derived stem cells (BMSCs).}

Spatial and time varying stress effects may improve tissue formation in TEHV constructs seeded with BMSCs. Recent studies in heart valve tissue engineering have used BMSCs because they are less invasive than other cell sources such as endothelial cells (ECs) or smooth muscle cells (SMCs). Comparison of these simulations with experimental data was performed.

\section{LITERATURE REVIEW}

\subsection{Heart Valve Disease}

Heart Valve disease (HVD) is any of the conditions in which the functioning of one or more of the native heart valves (NHVs) is affected. HVD can be caused by immune reactions, trauma, genetic and congenital factors as well as environmental factors such as diet, smoking habits, and sedentary life. It could affect any of the four valves such as the pulmonary ones [9-13]. There are four valves in the heart and they open and close in a synchronized manner permitting the blood to travel unidirectionally. The atrio-ventricular (A-V) valves (mitral and tricuspid) open when the pressure in the atrium exceeds the pressure in the ventricles and allows blood to flow inside the latter. In the same manner, when the pressure in the ventricles exceeds that of the atrium in the A$\mathrm{V}$ valves close. Subsequently, as ventricles contract, the pulmonary and aortic valves open allowing blood to flow towards the lungs and aortic artery respectively.

Valve stenosis occurs when the valves become stiff or fuse together. This

decreases the cross sectional area for blood to flow normally thereby affecting the 
hemodynamics. Another form of HVD is valve regurgitation. In this case, valves do not close properly and cause blood to flow back to the heart. As a consequence, blood flow to the body can be significantly diminished, therefore making the heart work harder $[14,15]$.

Pulmonary valves are responsible for allowing blood flow from the heart to the lungs for carbon dioxide and oxygen exchange. When the valve has undergone sufficient damage, it needs to be replaced by commercially available prosthetic heart valves. There are approximately 15000 pulmonary heart valve replacements each year [16]. In 1995, it was shown that it is possible to substitute single native pulmonary leaflets with tissue engineered leaflet constructs [17] in lambs. Other studies have reported using trileaflet constructs for grafting in sheep and it showed to last for up to 8 months before implant failure [17].

\subsection{Heart Valve prosthetics}

Prosthetic heart valves can be classified as either mechanical or bio-prosthetic. Mechanical heart valves (MHVs) are typically constructed out of a high strength material such as titanium or pyrolytic carbon. MHVs initial designs include the ball and cage, tilting disk, and the bileaflet versions. One of the bileaflet designs the St. Jude Medical $\mathrm{MHV}$, is the most widely used type of mechanical implant because of superior hemodynamics over the other two designs due to lower transvalvular pressure drop $[6,18,19]$. MHVs offer durability and reliability, but they have problems such as hemolysis and possible platelet activation due to abnormal hemodynamics [13,20,21]. MHVs are recommended for use in adults, but they are contraindicated for children because they do not account for somatic growth [14,22]. 
Bio-prosthetic valves (BPVs) are made of native valves explanted from animals or cadavers that have undergone proper standards of handling and processing in order to be used as human implants $[15,23]$. For xenografts, swines are the number one choice, but it can also be explanted from bovines $[13,15]$. Some of the problems that accompany xenografts or homograft valve implants are calcification and immune rejection which will lead to implant failure [24-27].

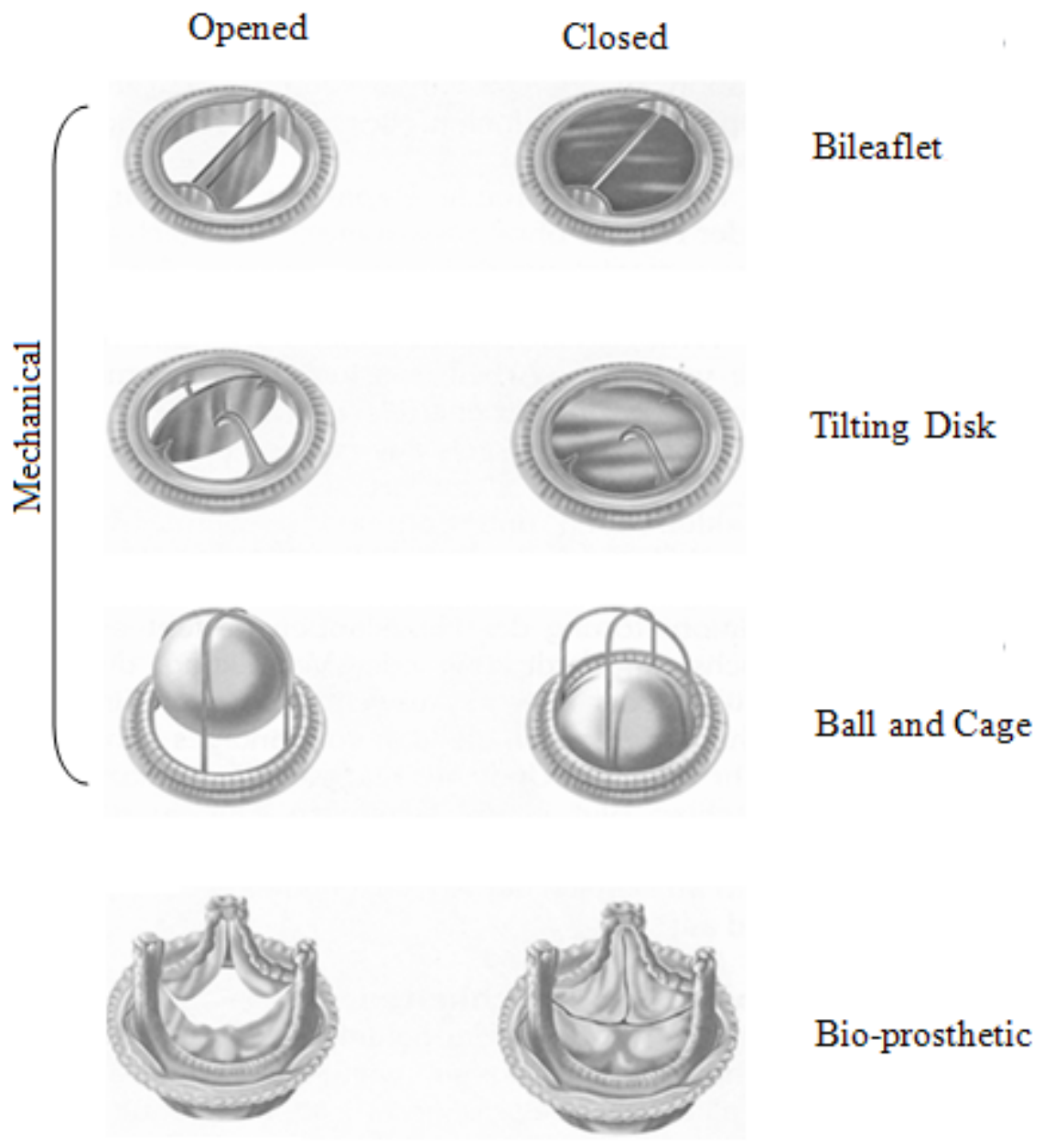

Figure 1. Mechanical and Biological Heart valves.

Heart valve tissue engineering aims at the development of an in-vitro implant with similar mechanical properties and anatomy as native valves. Moreover, a primary goal of 
this approach is to promote engineered tissue remodeling and growth [8]. However, no long term/ perpetual reliable engineered valve has been obtained thus far due to the complexity in mimicking the environments that native valves are exposed to $[1,28,29]$.

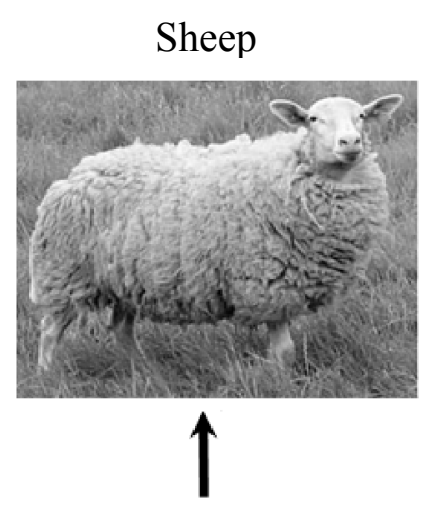

Conditioned implant

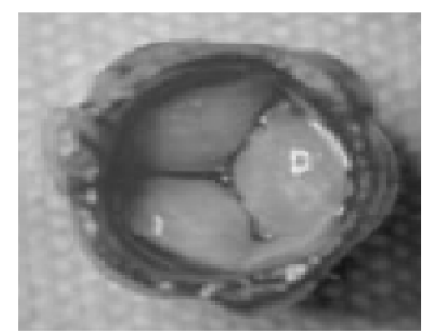

Autologous cells (i.e. BMSCs) Cell expansion
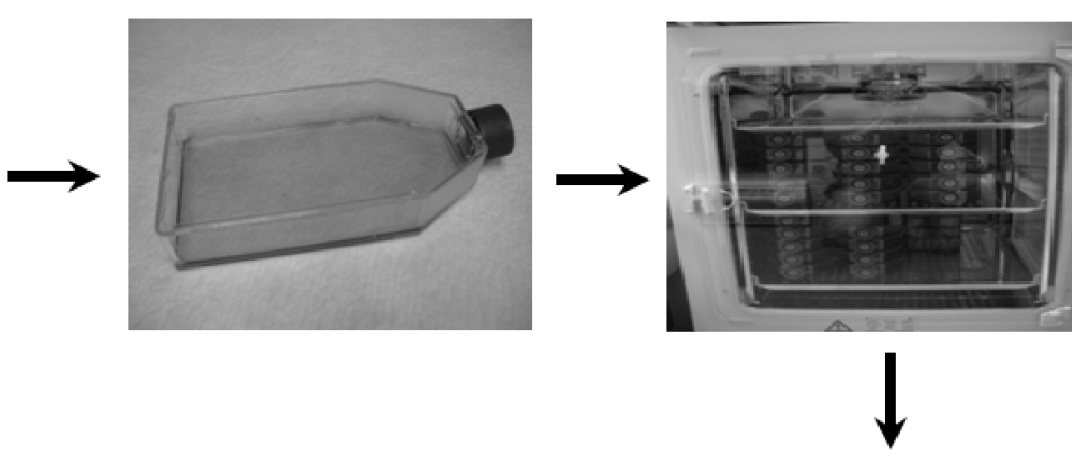

Cell seeding

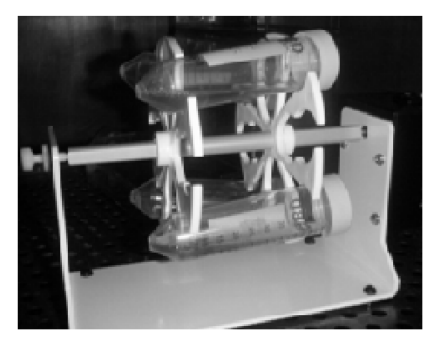

Figure 2. Tissue Engineering Approach

\subsection{Computational Fluid Dynamic in Heart Valves}

Through computational fluid dynamic (CFD) simulations, it has been shown that the flow physics acting on native heart valves can be replicated in rectangular scaffolds[7] Ramaswamy et al.[8] designed a custom made bioreactor able to induce flow, flexure and stress. The device was capable of housing up to twelve sample specimens. The design consisted of four u-tube shape pipe-like chambers of $13 \mathrm{~mm}$ diameters. Each chamber is capable of housing up to three samples. It was shown that the 
device was able to reproduce physiologically valid shear stress $\left(5-6\right.$ dynes $\left./ \mathrm{cm}^{2}\right)$ [8] while keeping laminar flow and low viscosity (1.27 centipoise).
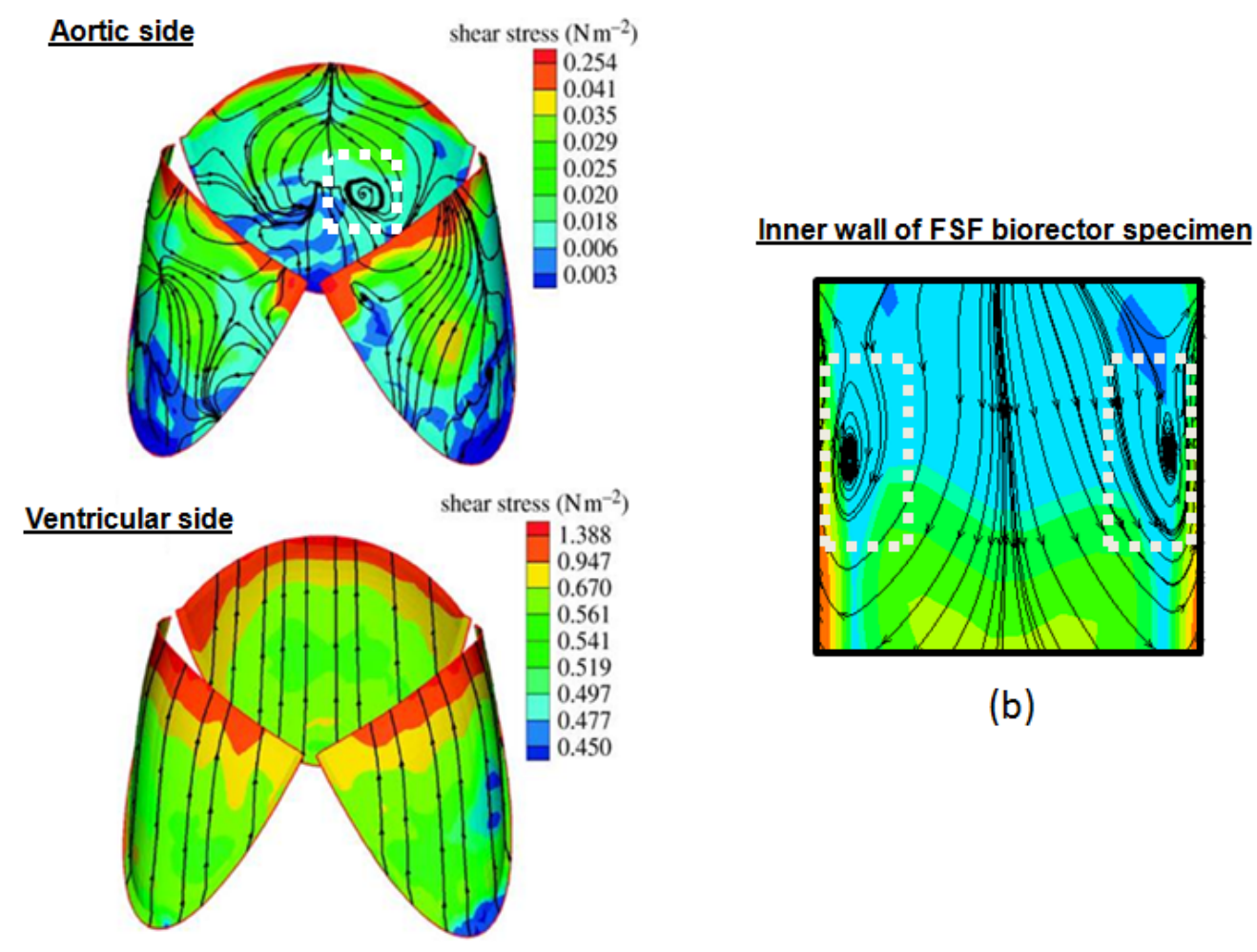

(b)

(a)

Figure 3. Computational fluid dynamic simulations on native heart valve (a) and rectangular (b) Geometries [7].

\subsection{Cell sources for HVTE}

Heart valve tissue engineering studies have been conducted using a variety of cell sources [30-33]. Some studies have focused on endothelial (ECs) and smooth muscle cells (SMCs). ECs and SMCs can be obtained primarily from vessels such as arteries. However, this is considered to be an invasive form of obtaining cells because vascular tissue is compromised and destroyed when extracting these two types of cells [31,34]. Nonetheless, these two cell sources have shown to promote tissue formation in studies pertaining to engineered heart valves. Human periodontal ligament derived stem cells 
(PDLSCs) [35] are another HVTE cell source. These cells are obtained mainly from wisdom teeth surgically extracted and can potentially adopt heart valve phenotypes. More recently, HVTE studies have used bone marrow derived mesenchymal stem cells (BMSCs) [32,33,36,37]. BMSCs are a practical source autologous progenitor cells because they can be obtained in large numbers in a minimally invasive manner [7,38].

\subsection{Scaffolds}

A fundamental aspect in tissue engineering is the use of scaffolds that mimic the mechanical and homeostatic conditions of NHVs. It is of utmost importance for cell and tissue development to have a suitable porous interface where colonizing cells can attach, replicate and produce ECM. Ideally, scaffold degradation rates should match the rate of mechanically resilient tissue formation [39]. HVTE studies have used polymeric and biological scaffolds. Polylactic acids (PLA), polyglycolic acid (PGA) have been used as artificial scaffold materials because of their biocompatibility and biodegradability $[33,40,41]$. These scaffolds can be easily constructed and therefore they can be obtained in an efficient manner [40]. However, the disadvantage is that these scaffolds do not match the mechanical properties of NHVs and simultaneously offer anatomically shape retention $[33,40,41]$.

Researchers have also investigated the use of decellularized biological scaffolds obtained from animal native valves [42]. One of the advantages of using these xenoconstructs is the conservation of the native heart valve architecture and ECM mechanical properties $[1,43]$. On the other hand, there are still unsolved compatibility issues. This is due primarily to the multi-factor interaction between cell sources such as BMSCs and decellularized extracellular tissue components such as collagen and other proteins $[1,3]$. 


\subsection{Mechanical Conditioning}

It is well documented that mechanical conditioning plays a role in the in-vitro development of vascular tissue [7,44,45]. Basic bioreactors provided dynamic conditioning in the form of fluid flow. These devices include compliance and ventricular chambers, pneumatic or peristaltic pumps, and sensors. They also use computers with specialized software for its monitoring. In some of these devices, pressure wave forms, velocities, and shear stress can be adjusted.

Sodian et al.[16] used a pulsatile bioreactor capable of inducing pulsatile flow and pressure. It was used to house tri-leaflet shaped polyhydroxyalkanoate (PHA) scaffolds seeded with vascular cells extracted from an ovine carotid artery. Histology showed a significant increase in cell proliferation and there was extracellular matrix (ECM) deposition in the fluid induced samples when compared to the static (no flow) samples. Moreover, cells were aligned in the direction of the flow. Additionally, there was presence of collagen and glycosaminoglycans (GAGs). However, there was no evidence of elastin production. It was not clear if the increase in tissue formation was caused by the increase number of cells or the pulsatility of the fluid. Evidence regarding phenotype changes was not reported.

Hoerstrup et al.[46] used a pulse duplicator bioreactor on tri-leaflet shaped scaffolds made of polyglycolic acid (PGA) and an outer coat of poly-4-hydroxybutyrate (P4HB). The constructs were seeded initially with ovine myofibroblasts with subsequent seeding of endothelial cells (ECs). Subsequently, the construct was implanted in lambs. Blood regurgitation due to inappropriate joining of the leaflets was observed soon after in-vivo grafting. 
Zeltinger et al. [47] used a bioreactor composed of a pneumatic pump used for inducing flow on a decellularized aortic valve from a porcine. Neonatal fibroblasts from humans were added to the flowing media and it continued to recirculate for 24 hours. The study demonstrated that decellularized scaffolds could be populated by colonizing cells. However, the construct failed due to valve stenosis, specifically by thickening of the cusps soon after implantation.

Sutherland et al. [29] developed a TEHV seeded with carotid artery-derived vascular smooth muscle cells (SMCs) and endothelial cells (ECs). The construct was implanted in sheep for up to 20 weeks. Cell differentiation towards a heart valve phenotype was observed after post-surgical examination.

Stickler, et al. [39] developed a device capable of cyclic stretch and implanted it on the peritoneal cavities in eight sheep. The implant was designed such that cells migrate to the scaffold. The results compared tissue samples cultured under static conditions versus cyclic stretching. It was determined that there was significantly more tissue formation in samples exposed to cyclic stretching, specifically that the mechanical properties of the tissue were enhanced by a factor of two.

Lichtenberg et al. [48] used a simple pulsatile bioreactor in order to mechanically stimulate a decellularized ovine pulmonary valve seeded with ECs. After ECs colonization of the scaffold, a continuous layered architecture was seen. Next, the graft was implanted in an ovine, and it performed satisfactorily at the initial stage. However, subsequent studies revealed onset of thrombosis and hyperplasia.

Ceborati et al. [49] collaborated with the Haverich's group [48] and conditioned two decellularized human pulmonary valves seeded with endothelial progenitor cells 
(EPCs). The grafts were implanted in two pediatric patients. Presently, the two patients have been observed to be in good health. Furthermore, the annulus of the graft has shown to have grown with the patient.

Despite the promising results mentioned above, there remain many uncertainties when looking at the future of TEHVs. It is well known that stem cells respond to chemical and mechanical cues, and that they phenotypic transformation can be guided. Mechanical stimulation has also shown to regulate the process of tissue formation. What it is not clear yet, is what specific flow physics is causing cells to produce more matrix and to differentiate viable progenitor cell types towards the heart valve lineage.

Custom bioreactors for HVTE studies are laboratory tissue-culture devices that can provide a controllable, mechanically active environment that can be used to study and potentially improve engineered tissue structure, properties, and integration. In some of these devices the individual or combined effects of flow, stretch, and flexure (FSF) stresses can be replicated and studied [38] In 2003, Engelmayr et al.[50] constructed a bioreactor designed to provide engineered tissue constructs with flexural stress conditioning. The biopolymeric scaffold was seeded with smooth muscle cells (SMCs). The results showed that there was a decrease in the flexural strength of the acellular scaffolds with increasing bending cycles. However, when the scaffold was seeded with SMCs, the flexural stresses augmented engineered tissue formation. 


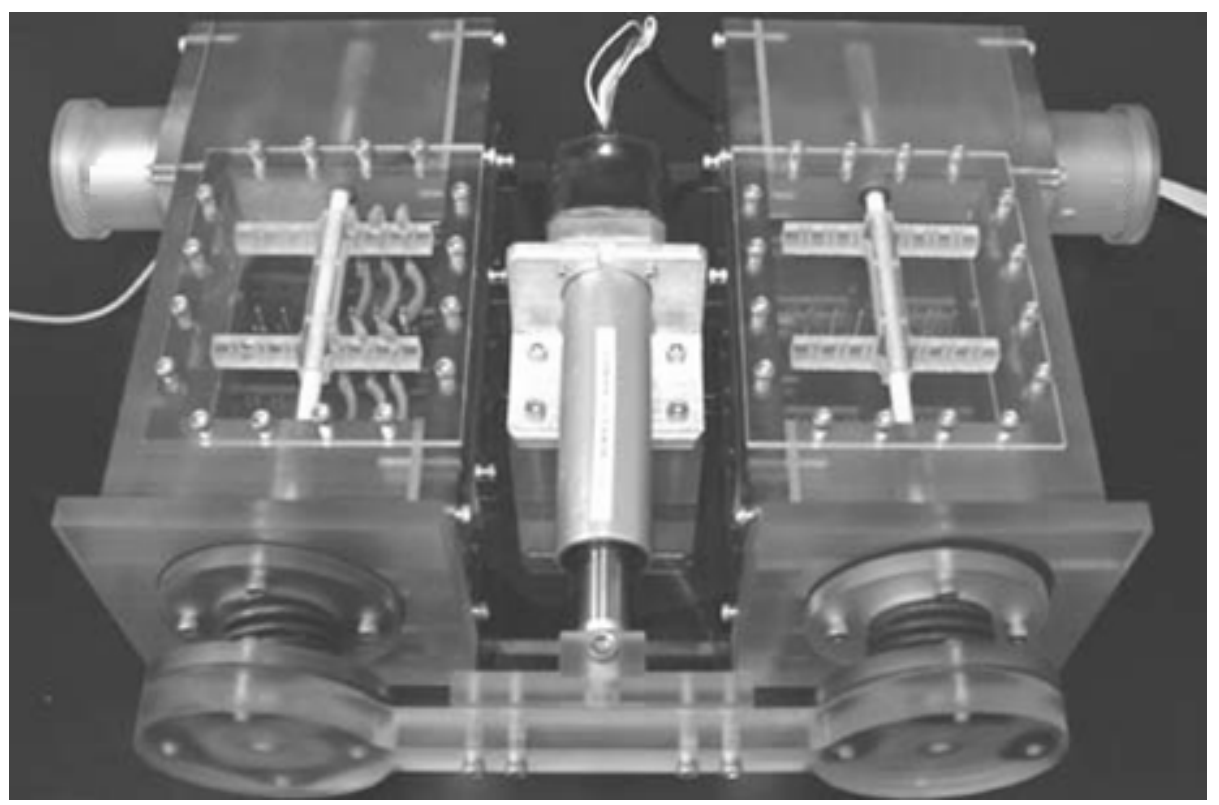

Figure 4. Custom made mechanical conditioning bioreactor for HVTE studies [38]. Modes: Flow, stretch, flexure.

Hildebrand et al.[51] developed a sophisticated bioreactor with a monitoring system capable of introducing controlled pressure and waveforms independently. It used a predictive control algorithm that could automatically modulate stroke volume, pump rate, systolic and diastolic pressures. The device could incorporate a wide range of pulsatile waveforms. Thus, it was able to condition grafts with physiologic and nonphysiologic flow conditions.

More recently, HVTE studies have used bone marrow derived mesenchymal stem cells (BMSCs). BMSCs are a practical source autologous progenitor cells because they can be obtained in large numbers in a minimally invasive manner $[7,45,52,53]$. Engelmayr, et al. [45] showed after 3 weeks of culture that, there was a significantly higher amount of engineered tissue formation derived from BSMC-seeded scaffolds under combined steady flow and flexure states, in comparison to steady flow or flexure alone and to static controls. This finding suggested that cyclic flexure creates specific 
flow environments in steady flow states that caused the cells to produce more ECM. Studies elsewhere have also provided evidence of flow vortices on the leaflets of native valves (aortic side) that seem to provide the physiological benefit of more complete valve closure[54,55]. More recently these vortices can be recapitulated in rectangular scaffolds that have a bent configuration $[7,45]$ and have been shown to be analogous to vortices observed in tri-leaflet heart valves.

Ramaswamy et al. $[7,45]$ had previously proposed the hypothesis that oscillatory shear stress (OSS) caused by time-varying flow environments, triggered by bending geometries, play a critical role in engineered tissue formation derived from BMSCs. There is strong evidence to support this hypothesis in other tissue engineering applications such as bone. Specifically, OSS has been shown to influence BMSCs proliferation and upregulate transcription factors responsible for phenotypic regulation [52,56-59]. In particular, Li et al. [53] reported that OSS caused triggering of intracellular calcium mobilization in BMSCs and regulation of osteogenic gene expression. These findings translate to HVTE studies using BMSCs and may potentially augment engineered tissue formation rates and supporting the heart valve phenotype.

It was noted that from observing native heart valve dynamics that from a biomimetic standpoint, OSS can be created by means of pulsatility or by cyclic specimen geometry changes. However, quantification of the individual or combined effects of these variables to maximize OSS environments in vitro is to date, not known. Accordingly, this study, examined and quantified the role that i) physiologically relevant scales of pulsatility and ii) changes in geometry as a function of specimen flexure, have in creating OSS conditions for dynamic culture of tissues. This work will allow for the study of 
valve like configurations and flow environments and the subsequent comparison of the surrounding 3-D flow physics under steady and pulsatile conditions. This will permit the identification of specific fluid environments that may play a role in engineered heart valve tissue formation.

\section{METHODS}

\subsection{Methodology for aim 1 and 2}

\subsubsection{Initial Geometry and meshing for all simulations/fluid properties}

Previous efforts have focused on the development of a u-shaped bioreactor capable of inducing flow, flexure and tension on rectangular scaffolds (Fig. 5A) [8]. The fluid domain of the u-shape bioreactor was constructed (Fig. 1D) through Ansys ${ }^{\mathrm{TM}}$ commercial software (Ansys Inc, Canonsburg, PA). The mesh was constructed with tetrahedral elements (Fig. 6A) Physical properties for bioreactor media were used with

density $=1.01 \mathrm{~g} \mathrm{~cm}^{3}$ and dynamic Viscosity $=1.27$ centipoise. Simulations were run in a Hewlett Packard ${ }^{\mathrm{TM}}$ work station with intel(R) Xeon(R) CPU, x5550@ 2.67GHz (2processors) with $16.0 \mathrm{~GB}$ installed memory and 64-bit windows 7 operating system. 


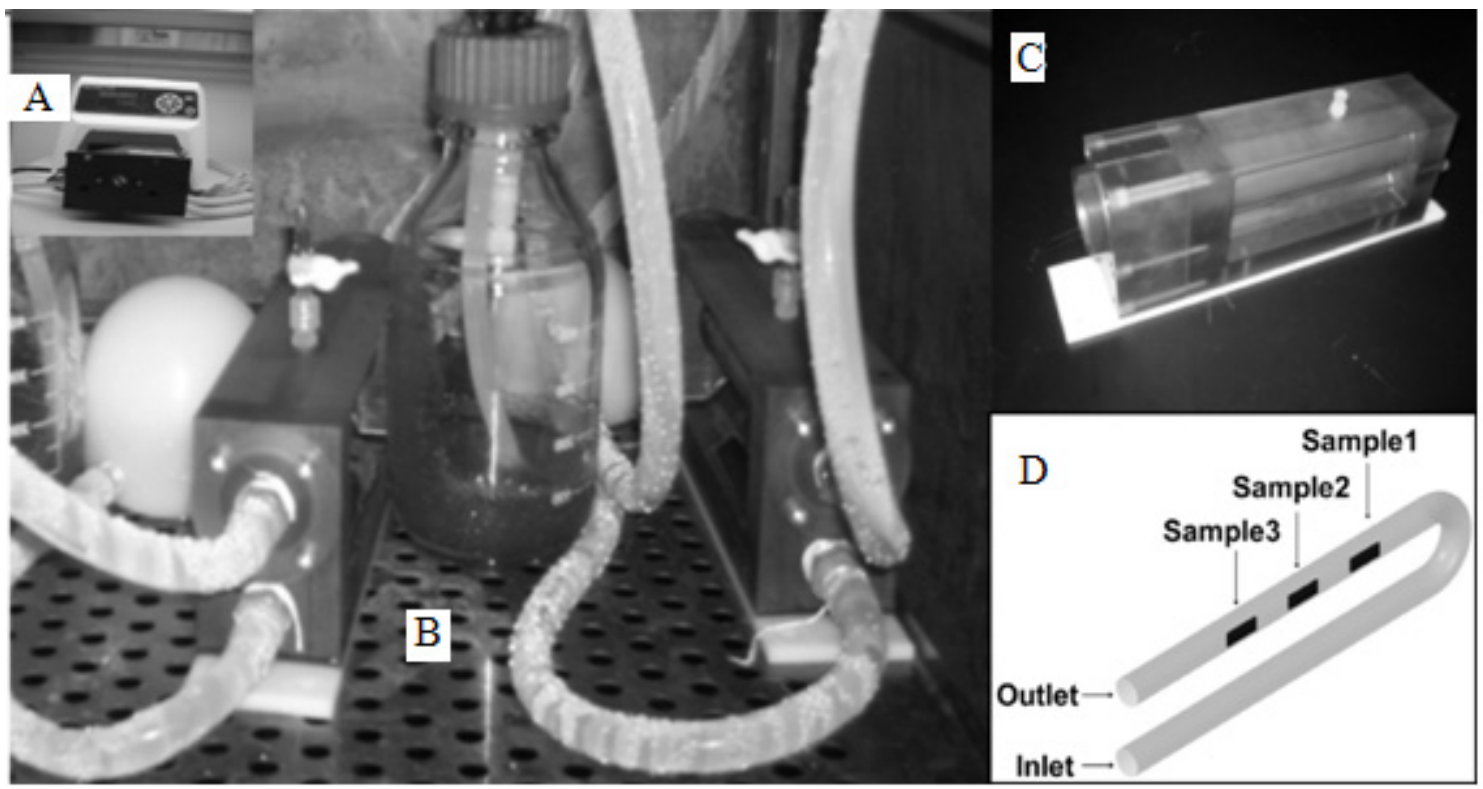

Figure 5. (A) Peristaltic pump used to induce flow through the FSF bioreactor. (B) FSF bioreactor set up. (C) Single FSF bioreactor chamber. (D) Bioreactor fluid domain showing the position of the three rectangular specimens.

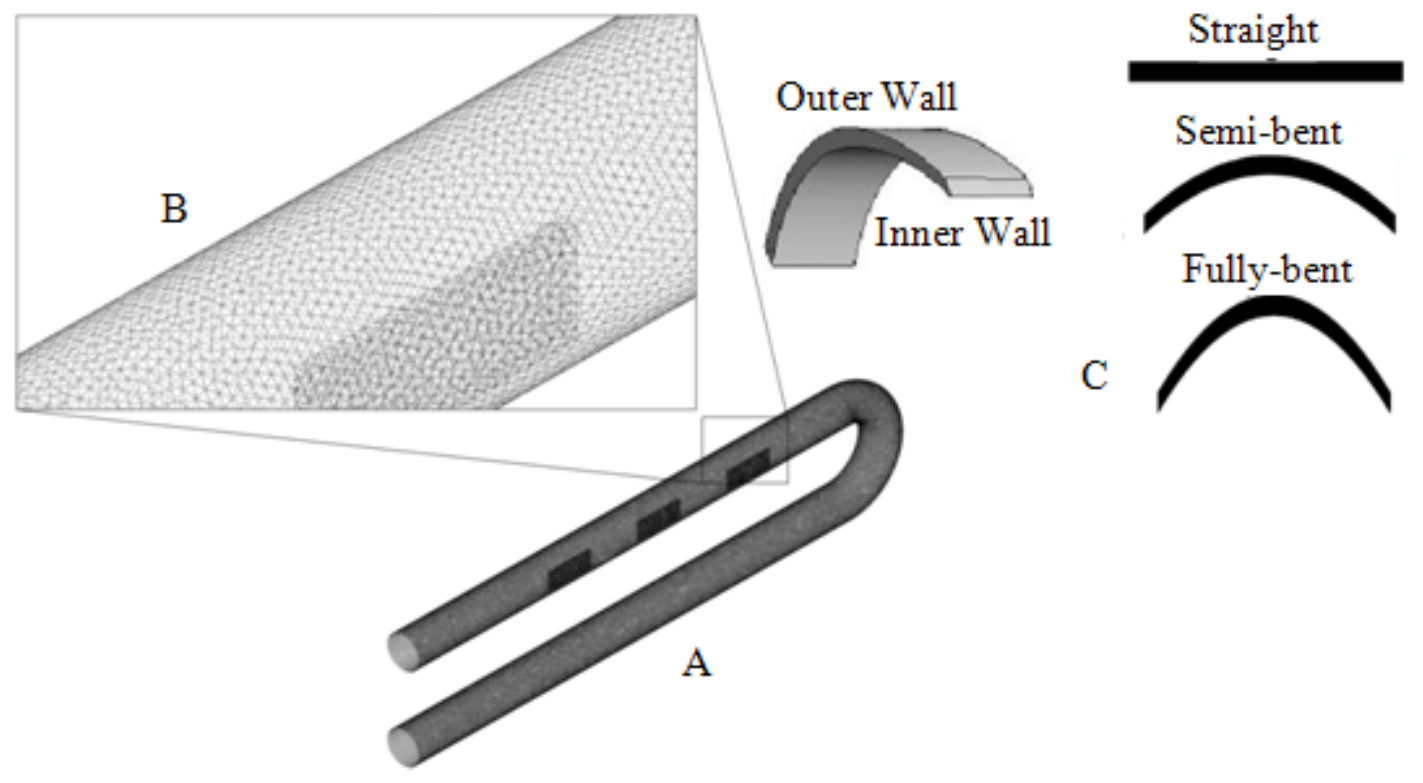

Figure 6. (A) Tetrahedral mesh with $3.1 \times 10^{6}$ elements and $5.5 \times 10^{5}$ nodes. (B) Close up of the mesh near the sample region. (C) Sample showing inner and outer wall and the specimen straight, semi-bent, and fully-bent geometries. 


\subsubsection{Displacement and Non-linear constant calculations}

In the u-shaped bioreactor, the three rectangular- shaped specimens was fixed on one end and permitted to move linearly with the use of an actuator (UltraMotion, Cutchogue, NY) from the other end. The actuator moved 0.5 inches forward in 0.5 seconds and 0.5 inches back to the initial position in the next 0.5 seconds. Therefore, the duration of one full cycle is one second (frequency of $1 \mathrm{~Hz}$ ). A fortran code was written using the equations that govern the actuator displacement, and 250 displacement values were obtained at an interval of 2 milliseconds. These values represented the axial displacement of the actuator for half a cycle (0.5 seconds). Specimens were assumed to take a parabolic shape and fit to the arc equation, given by:

$$
\int_{-8.5}^{b} \sqrt[2]{1+(C x)^{2}} d x=17 m m
$$

Where $\mathrm{b}$ is the new position of the moving end as it moved to the stationary end and $\mathrm{C}$ is the nonlinear parabolic constant. The shape conformed to the equation of an arc with the constraint of a fixed specimen axial length of $17 \mathrm{~mm}$. In this way, the sample length was preserved at each axial displacement and the nonlinear constant is obtained. The constant, "C" was computed numerically in Mathcad" (v.15, PTC, Needham, MA) over a total of 250 time steps.

\subsubsection{Tests for Independence}

Independence tests were performed on meshing, time step, and periodicity for steady and pulsatile simulations accordingly. As the monitored variable, the area averaged wall shear stress on the samples was used. A 5\% error acceptance criterion in comparison with highly resolved simulations was employed. 


\subsubsection{Methodology for aim 1- Steady state simulations}

From the 250 spatial positions, efforts focused on building an initial mesh at $\mathrm{t}=$ 0 (fully straight state) and 10 subsequent meshes equally spaced, such that the last mesh corresponded to the fully flexed state $(\mathrm{t}=0.5 \mathrm{~s})$. The time step between these meshes was $50 \mathrm{~ms}$. In this manner a quasi-static analysis of the flow field across these 11 static meshes was conducted. The boundary condition at the inlet was specified to be a plug velocity of $2.2 \mathrm{~cm} / \mathrm{s}$. Also, the outlet was set to an opening static pressure of $0 \mathrm{~Pa}$.

\subsubsection{Methodology for aim 2- Static pulsatile simulations}

For the pulsatile simulations, a pulmonary artery flow rate waveform obtained from Lotz et. al. [60] was used. The waveform had a total duration of 1.2 seconds for one full cycle, and it was adjusted such that it has duration of one second. This was done because previous calculations for the axial displacements and non-linear constants used a 1-second cycle (Fig. 7a). Subsequently, the waveform was conversed to time (seconds) vs velocity $(\mathrm{cm} / \mathrm{s})($ Fig. $7 \mathrm{~b})$ and used as the inlet velocity profile.

Flow Rate Waveform

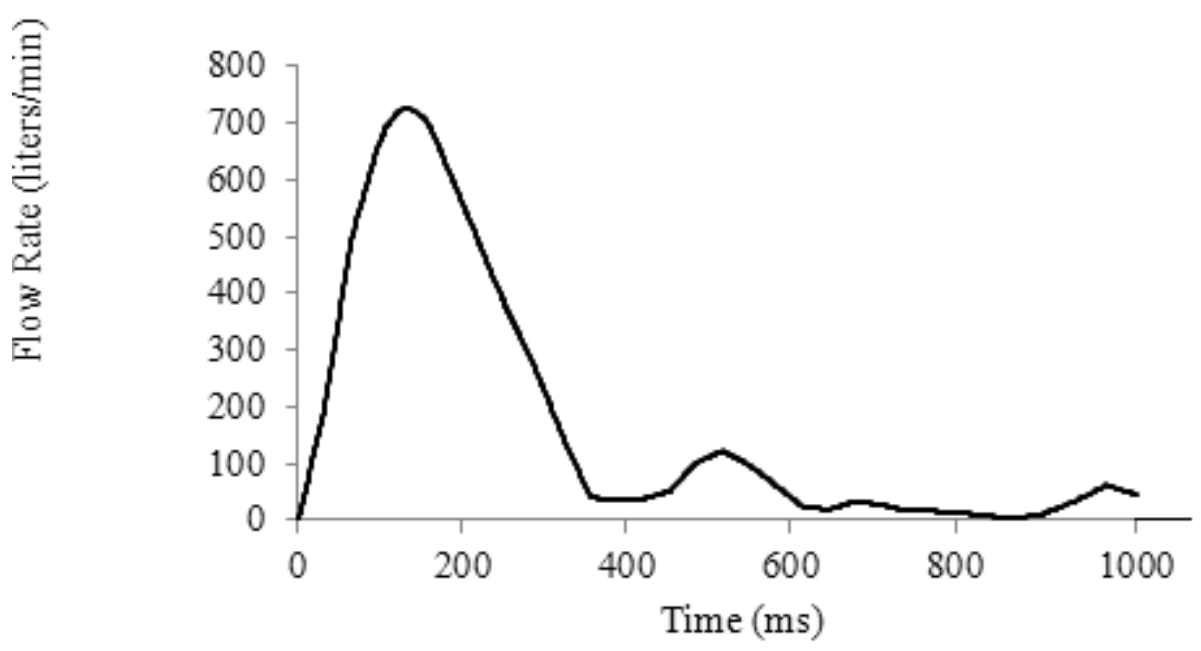

(A) 


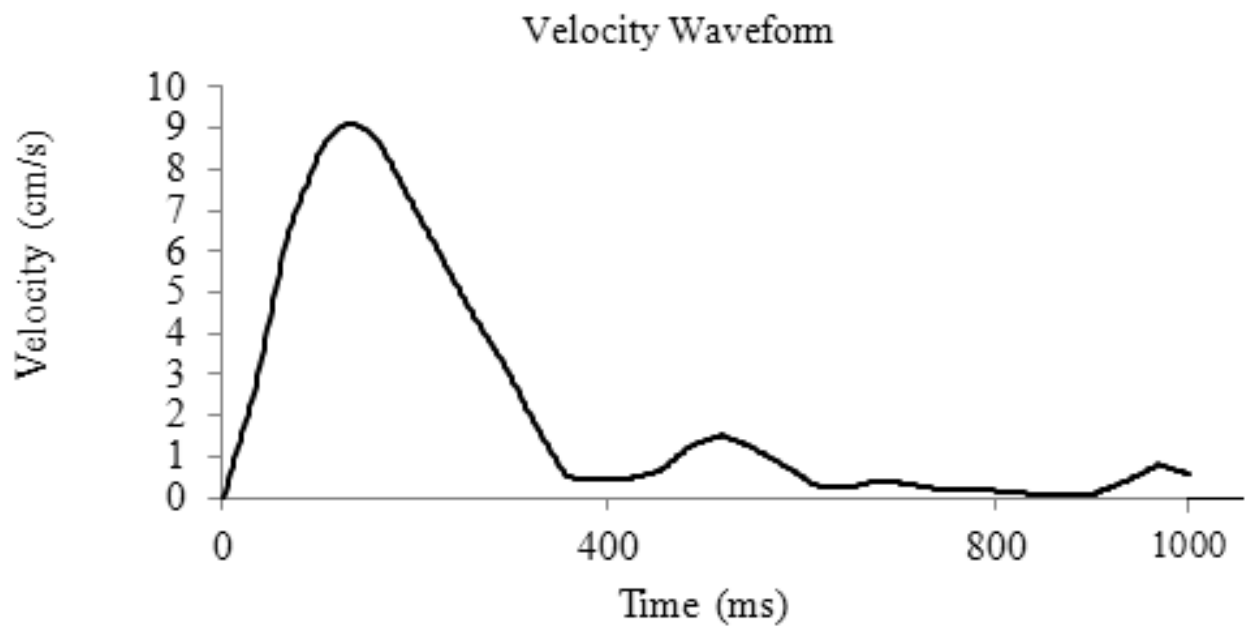

(B)

Figure 7. A) Flow rate waveform adjusted from $1.2 \mathrm{sec}$ (original from lotz, et. at.[60] ) to 1 sec. B) Velocity waveform with a velocity average of $0.199386 \mathrm{~cm} / \mathrm{s}$.

\begin{tabular}{|lll|}
\hline & Steady & Pulsatile \\
\hline Flow & Laminar Flow & Laminar Flow \\
\hline Walls & Walls-No slip conditions & Walls-No slip conditions \\
\hline Inlet & $\begin{array}{l}\text { Plug velocity } \\
0.02 \mathrm{~m} / \mathrm{s}\end{array}$ & Velocity waveform \\
\hline Outlet & $\begin{array}{l}\text { Outlet-Opening pressure } \\
=0 \text { Pa }\end{array}$ & $\begin{array}{l}\text { Outlet-Opening pressure } \\
=0 \text { Pa }\end{array}$ \\
\hline Convergence & $5 \times 10^{-5}$ & $5 \times 10^{-5}$ \\
\hline
\end{tabular}

Table 1. Parameters for steady and pulsatile simulations.

\subsubsection{Oscillatory Shear Stress}

Oscillatory shear stresses were quantified by means of an oscillatory shear index (OSI), as described by $\mathrm{He}$ and $\mathrm{Ku}[61]$. OSI can be obtained by using the following equations. 
$O S I=\left(\frac{1}{2}\right)\left(1-\frac{\int_{0}^{T} \tau d t}{\int_{0}^{T} a b s(\tau) d t}\right)$

Where

$\int_{0}^{T} \tau d t=$ The magnitude of the time averaged shear stress $\quad$ Eq.6

In the quasi static analysis $\int_{0}^{T} \tau d t$ can be obtained by using the following equation:

$\sqrt{\left(\frac{\sum_{i=0}^{11} S S x_{i}}{11}\right)^{2}+\left(\frac{\sum_{i=0}^{11} S S y_{i}}{11}\right)^{2}+\left(\frac{\sum_{i=0}^{11} S S z_{i}}{11}\right)^{2}}$

Likewise, $\int_{0}^{T} a b s(\tau) d t$ can be obtained as follows:

$\sqrt{\frac{\sum_{i=0}^{11}\left(S S x_{i}+S S y_{i}+S S z_{i}\right)^{2}}{11}}$

Eq. 8

Where

$S S x_{i}=\mathrm{x}$ component of shear stress

Eq.9

$S S y_{i}=\mathrm{y}$ component of shear stress

Eq. 10

$S S z_{i}=\mathrm{z}$ component of shear stress

$i=1,2,3 \ldots 11$ represents the number of each of the eleven sample geometries where 1 represents the number of each of the eleven sample geometries.

$i=1,2,3 \ldots 11$ represents the number of each of the eleven sample geometries where 1 represents the straight geometry and 11 represents the fully bent position. 
For the pulsatile case $\int_{0}^{T} \tau d t$ and $\int_{0}^{T} a b s(\tau) d t$ can be obtained by using equation Eq. 7 and Eq.8. In this case,

$i=1,2,3 \ldots 11$ represents 11 waveform time points evenly spaced, where 1 represents time at $\mathrm{t}=0$ and 11 represents time at $\mathrm{t}=1$ second.

\subsection{Methodology for aim 3- Cell Culture experiments}

4.2.1 Cell Differentiation: BMSCs were cultured in $\mathrm{T}-75$ flasks in a $37^{\circ} \mathrm{C}$ incubator until $100 \%$ confluence was reached. The cells were split to obtain a cell density of $17 \times 10^{6}$ cells $/ \mathrm{cm}^{2}$ and cultured for an additional week. Group 1(n=4) contained BMSC cultured in a 96 well-plate under static flow. Group $2(n=4)$ this group of BMSCs was cultured in the Bioflux 200 system (Fluxion Biosciences, San Francisco, CA) and exposed to steady flow with a shear stress of $1.5 \mathrm{dyn} / \mathrm{cm}^{2}$. Group $3(\mathrm{n}=4)$ - contained BMSCs cultured in the Bioflux 200 system and exposed to a pulsatile shear stress obtained from a physiological pulmonary valve waveform [60].

4.2.2 Culture Media: The media contained DMEM High glucose (Invitrogen, Carlsbald, CA), 10\% fetal bovine serum (ATCC, Manasas, VA), 1\% antibiotic/antimycotic, 1\% HEPES (Invitrogen, Carlsbald, CA), $2 \eta \mathrm{g} / \mathrm{mL}$ of basic fibroblast growth factor (bFGF, Invitrogen, Carlsbald, CA), $82 \mu \mathrm{g} / \mathrm{mL}$ Ascorbic Acid (Sigma-Aldrich, St. Louis, MO). The media was changed every 24 hours for a period of one week. The amount of media added to each well for the 24-microfluidic well plate, was $3 \mathrm{ml}$, and for the $96-$ well plate (group 1) was $200 \mu \mathrm{L}$. The $82 \mu \mathrm{g} / \mathrm{mL}$ of Ascorbic acid was added to the media.

4.2.3 Bioflux 200 System: The Bioflux 200 system consists of a pneumatic pump, a 24microfluidic well plate, a 24-well plate interface, and a user operated software. The 
system allows inputting the desired shear stress for both continuous and pulsatile flow. The Bioflux 200 is connected to a microscope with a CCD camera allowing the user to take photographs of the cultured cells under flow. This system is efficient for stem cell applications, such as cell differentiation.

\subsubsection{Assays:}

Cell Differentiation-RNA Isolation and Reverse Transcription: SMCs were washed with PBS and removed from the T- $75 \mathrm{~cm}^{2}$ flask (Fisher Scientific, PA) by $0.25 \%$ TrypsinEDTA (ATCC, Manasas, VA). Then, the detached cells were gathered in a $15 \mathrm{ml}$ conical tube (Fisher Scientific, PA). In order to perform the RNA isolation procedure, the cells were transferred to a $1.5 \mathrm{ml}$ RNAase free tube. Total mRNA was purification of mRNA was performed through the SV Total RNA Isolation System (Promega, Madison, WI). Reverse transcription reaction was performed on $1 \mu \mathrm{g}$ of total mRNA with GoScript ${ }^{\mathrm{TM}}$

Reverse Transcription System (Promega, Madison, WI). Detection was performed by using a Step One Real-Time PCR System (Applied Biosystems, Carlsbad, CA). The cycling parameters were 950C, 5 seconds; 600C, 45 seconds; 950C, 15 seconds.

\subsubsection{Statistics}

Independent two sample t-test

$$
t=\frac{\overline{x_{1}}-\bar{x}_{2}}{\left(S_{X_{1} X_{2}}\right) \sqrt{\frac{2}{n}}}
$$

Where

$$
S_{X_{1} X_{2}}=\sqrt{\frac{1}{2}\left(S_{X_{1}}^{2}+S_{X_{1}}^{2}\right)}
$$


$S_{X_{1}}^{2}=$ variance of first group

$S_{X_{2}}^{2}=$ variance of second group

Degrees of freedom $=2 n-2$

$\mathrm{n}=$ number of samples

Assumptions:

Equal variance

\section{RESULTS FOR AIM 1 AND AIM 2}

CFD simulations were run with the U-shaped tube geometry, housing three rectangular specimens that depicted a conditioning chamber of the bioreactor. Solution convergence was achieved at the prescribed residual values for continuity and motion equations $\left(<5.0 \times 10^{-5}\right)$. Uniformity in shear stresses between specimens $(\mathrm{N}=3$ specimens) housed within the bioreactor was observed and was found to be consistent with previous studies [8] inter-specimen variation of shear stresses was all found to be within 5\% in all simulations performed.

As shown in Figure 8, there is higher variability of shear stress magnitude in the outer wall of the samples for both pulsatile and quasi-static scenarios. The outer walls show higher shear stress at the upstream region when compared to the downstream area. Average inner wall specimen shear stresses $(\mathrm{N}=3)$ were found to be $0.05 \mathrm{~Pa}$ (straight), $0.09 \mathrm{~Pa}$ (semi-bent) and 0.1 Pa (fully-bent), whereas the time-averaged shear stress over 11 specimen configurations was found to be $0.03 \mathrm{~Pa}$ (quasi-static) (Fig. 9). Average outer wall shear stresses were $0.05 \mathrm{~Pa}$ (straight-pulsatile), $0.12 \mathrm{~Pa}$ (semi-bent-pulsatile), 0.17 $\mathrm{Pa}$ (fully-bent-pulsatile), and a time-average shear stress of $0.11 \mathrm{~Pa}$ was computed from 
the quasi-static analysis (Fig. 9). In brief, the outer wall shear stress is higher when compared to the inner wall. This is due to higher momentum forces acting on the outer surface due to the moving flow that encounters it.

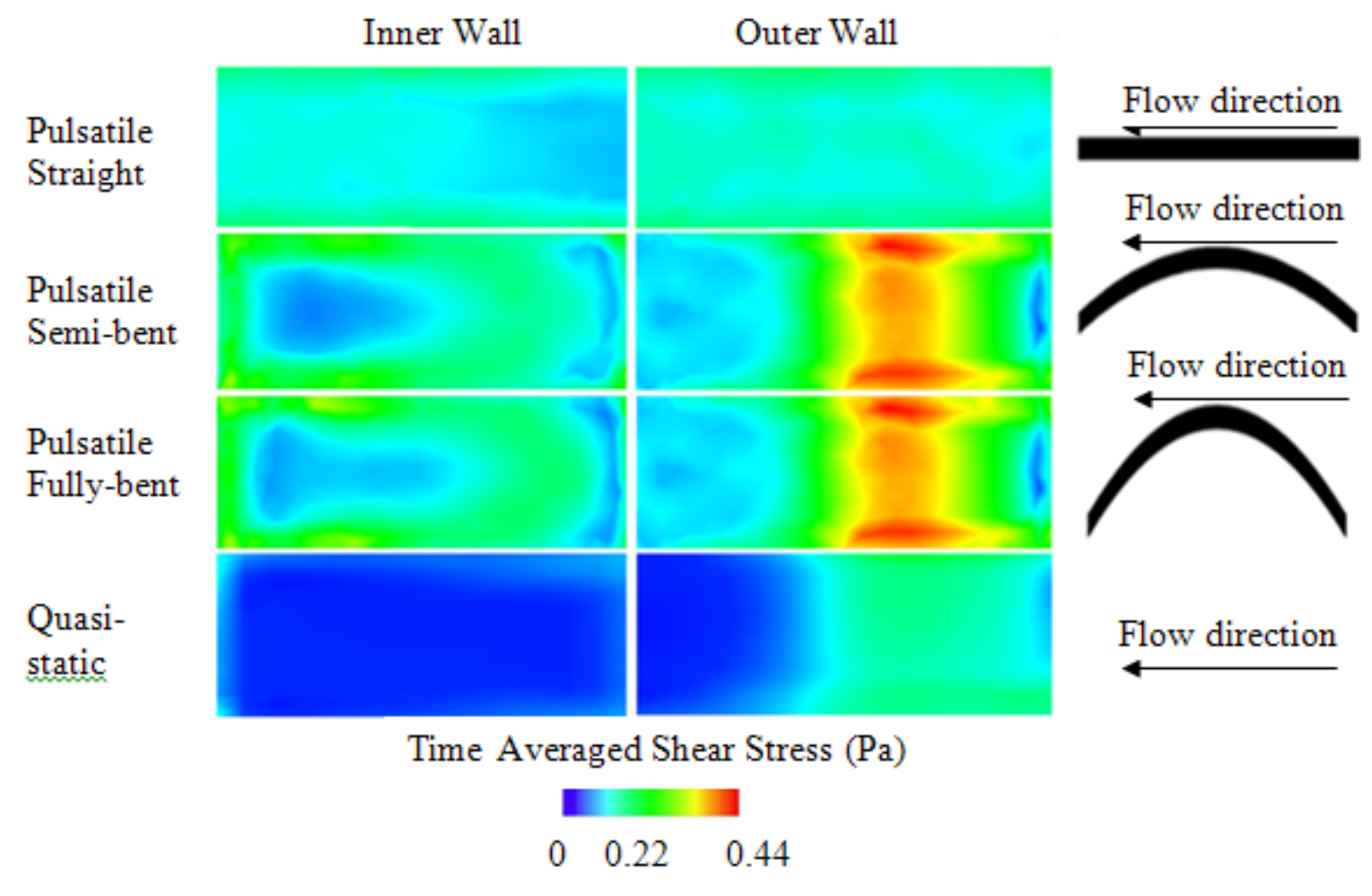

Figure 8. Time averaged wall shear stress distributions in the inner $(n=3)$ and outer $(n=3)$ walls of the specimen for three geometry positions under pulsatile and quasi-static conditions. 
Time Averaged Shear Stress in the inner and outer walls

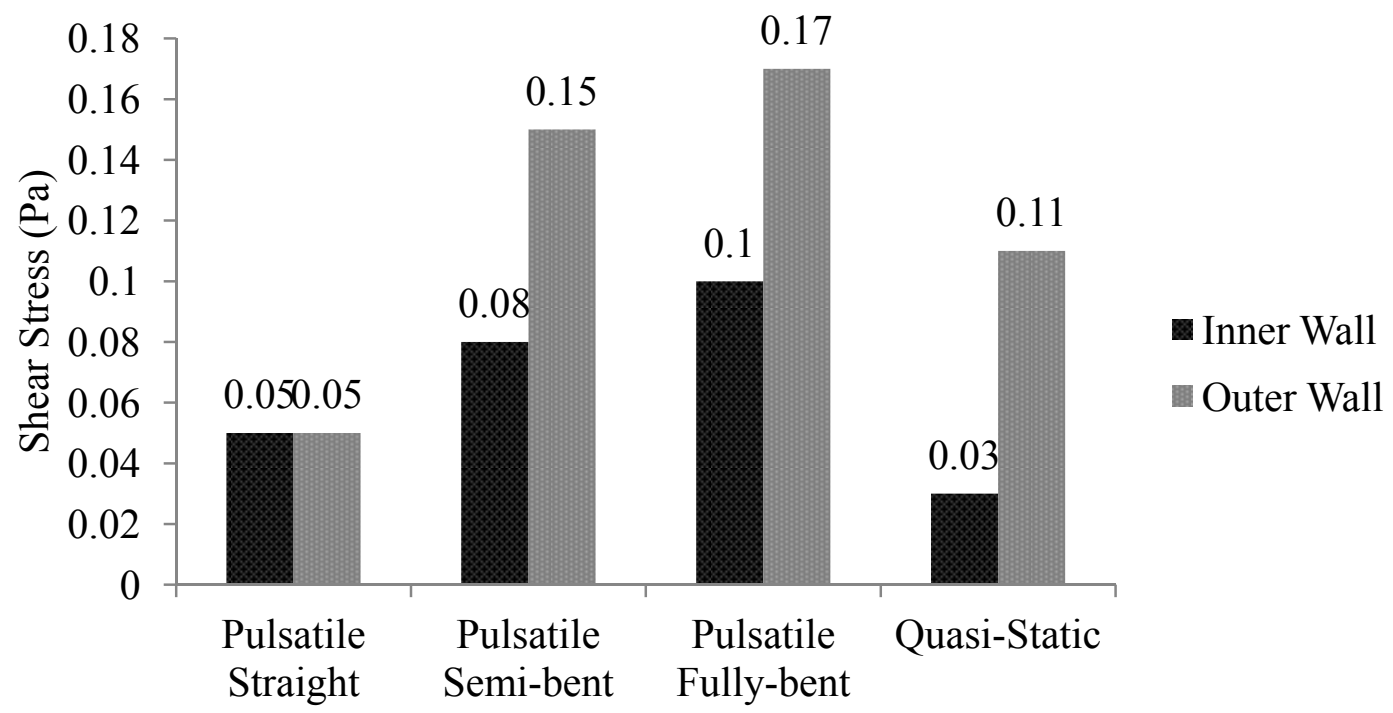

Figure 9. Bar chart showing time averaged shear stress.

The direction of the shear stress vectors at different instantaneous velocities in one full cycle was observed (Fig 10-16). Particularly, observations were performed at the higher velocity range in the waveform because there are more fluid environments alterations in this area. Specifically, three time intervals during the acceleration phase $(\mathrm{t}$ $=0.028 \mathrm{sec}, \mathrm{vel}=2.9 \mathrm{~cm} / \mathrm{s} ; \mathrm{t}=0.05 \mathrm{sec}, 2.9 \mathrm{~cm} / \mathrm{s} ; \mathrm{t}=0.1, \sec 5.2 \mathrm{~cm} / \mathrm{s}$ ) were observed, maximum velocity $(\mathrm{t}=0.13, \sec 8.9 \mathrm{~cm} / \mathrm{s})$, and three time intervals during the deceleration phase $(\mathrm{t}=0.168 \mathrm{sec}, 7.6 \mathrm{~cm} / \mathrm{s} ; \mathrm{t}=0.256 \mathrm{sec}, 5.2 \mathrm{~cm} / \mathrm{s} ; \mathrm{t}=0.314, \mathrm{sec} 2.9$ $\mathrm{cm} / \mathrm{s}$ ). It was observed that in the straight samples (Fig 6,7) shear stress vectors travel in the same direction as the flow during the acceleration period. On the other hand, these vectors were found to be in the complete opposite direction to the flow during the deceleration phase. For the case of the semi-bent and fully bent cases, it was observed 
that the wall shear vectors change direction even at the acceleration phase. This is particularly visible at the inner walls.
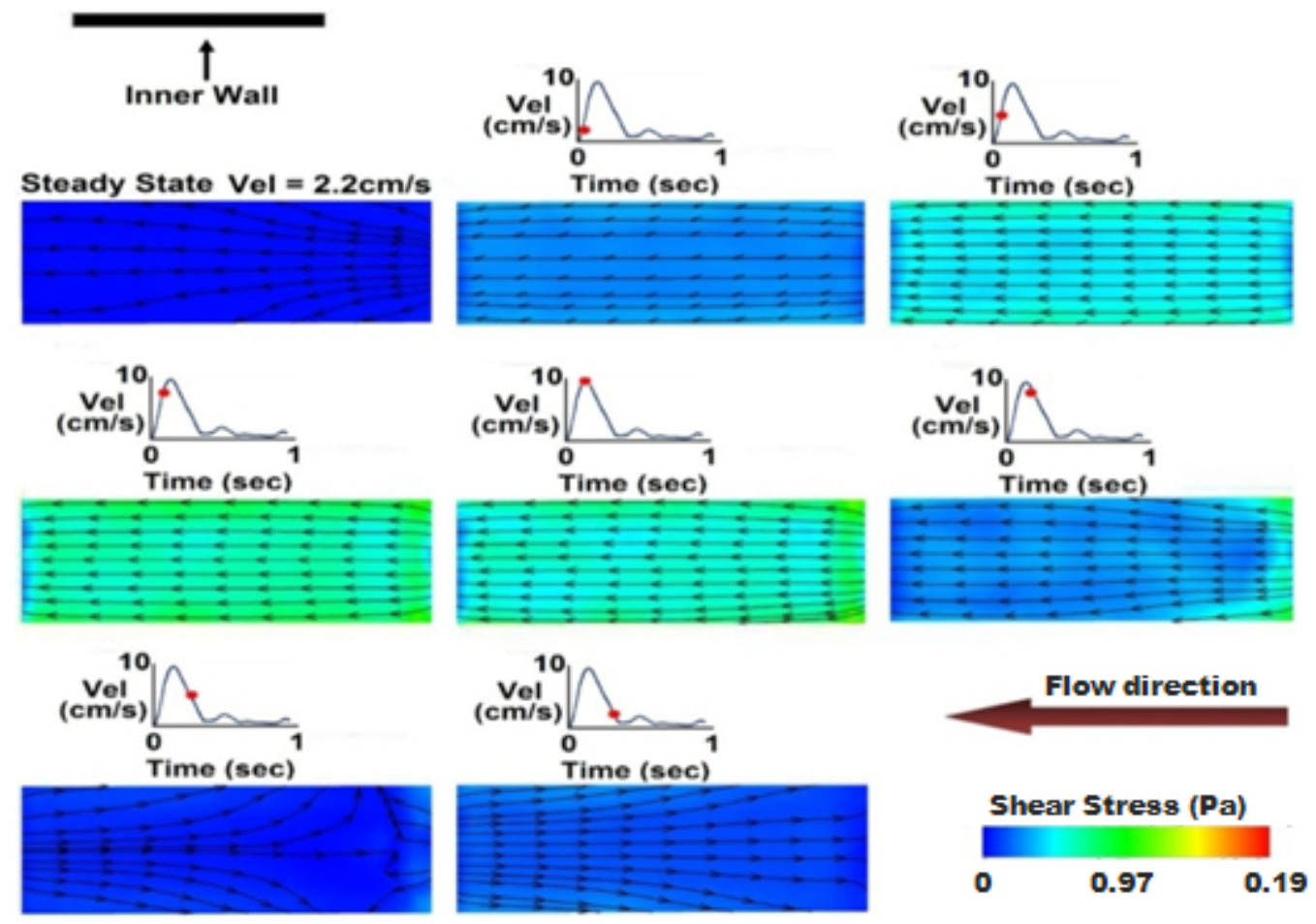

Figure 10. Inner wall of a straight sample shear stress magnitude with superimposed wall shear vectors. 


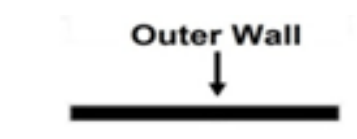

Steady State $\mathrm{Vel}=2.2 \mathrm{~cm} / \mathrm{s}$
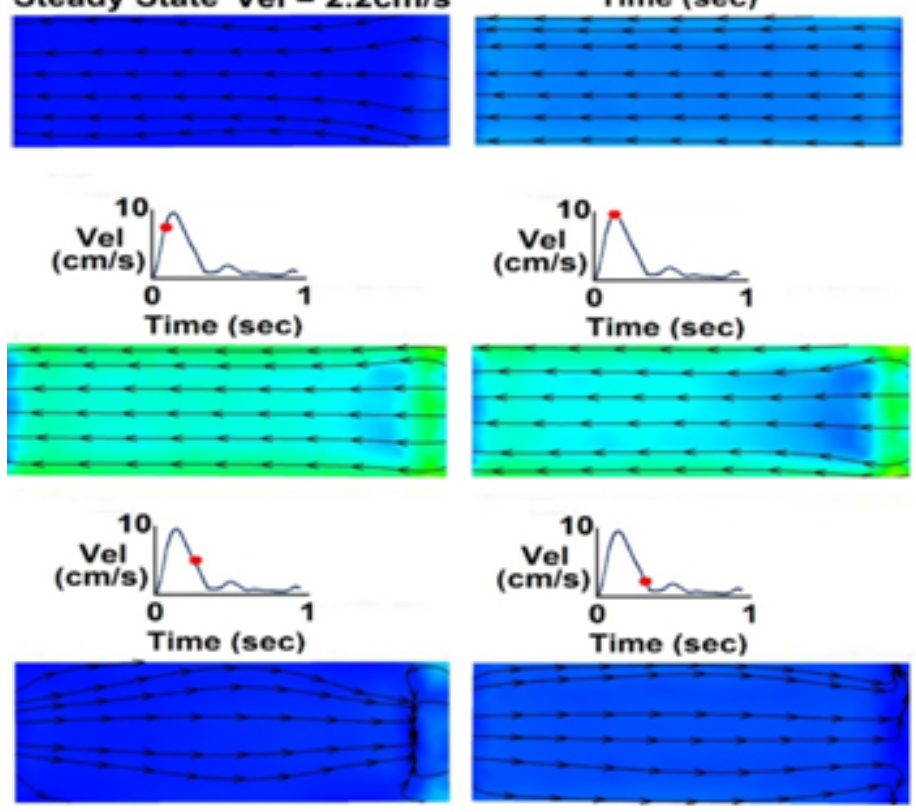

Figure 11. outer wall of a straight sample shear stress magnitude with superimposed wall shear vectors.
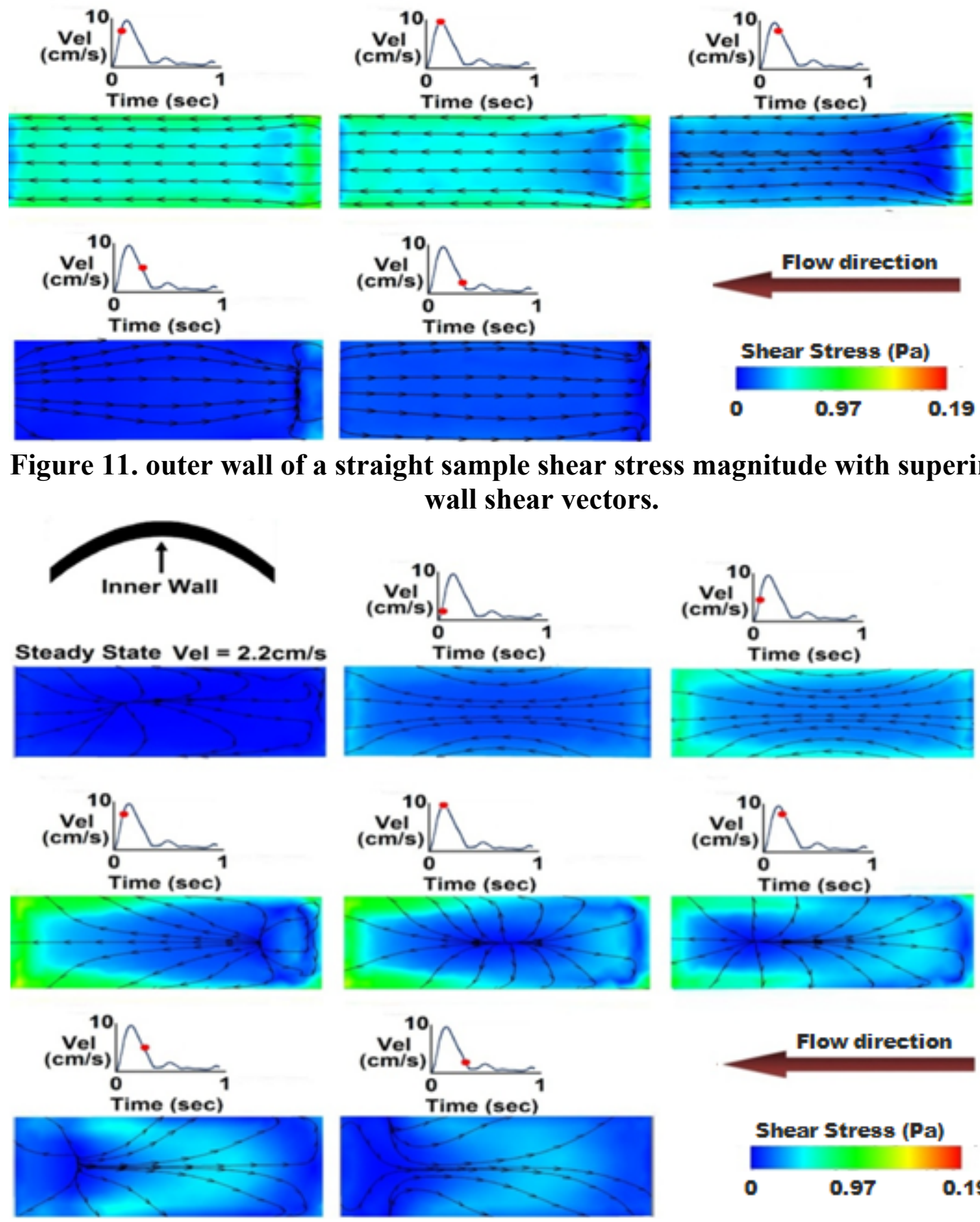

Figure 12. Inner wall of a semibent sample shear stress magnitude with superimposed wall shear vectors. 

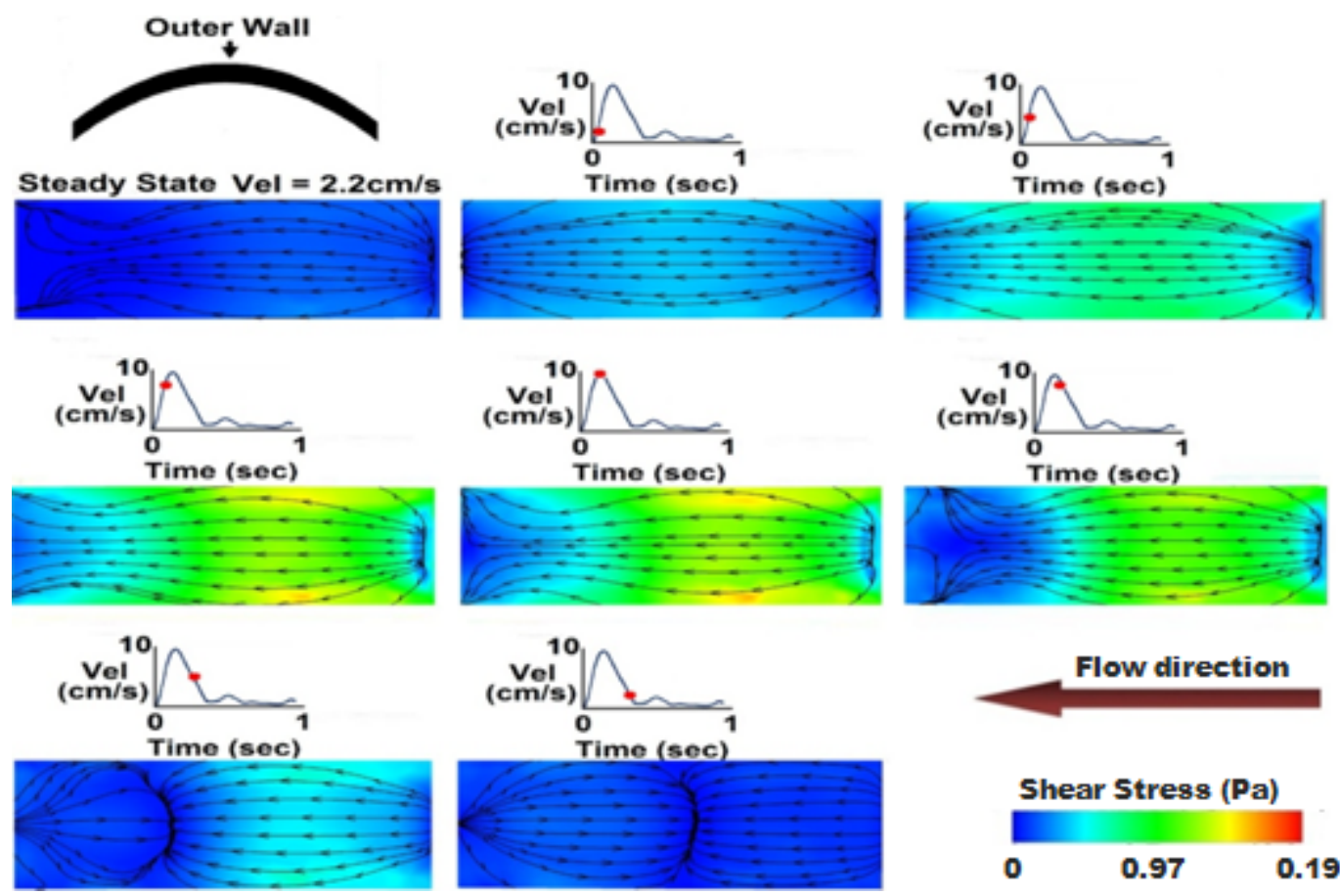

Figure 13. Outer wall of a semibent sample shear stress magnitude with superimposed wall shear vectors.
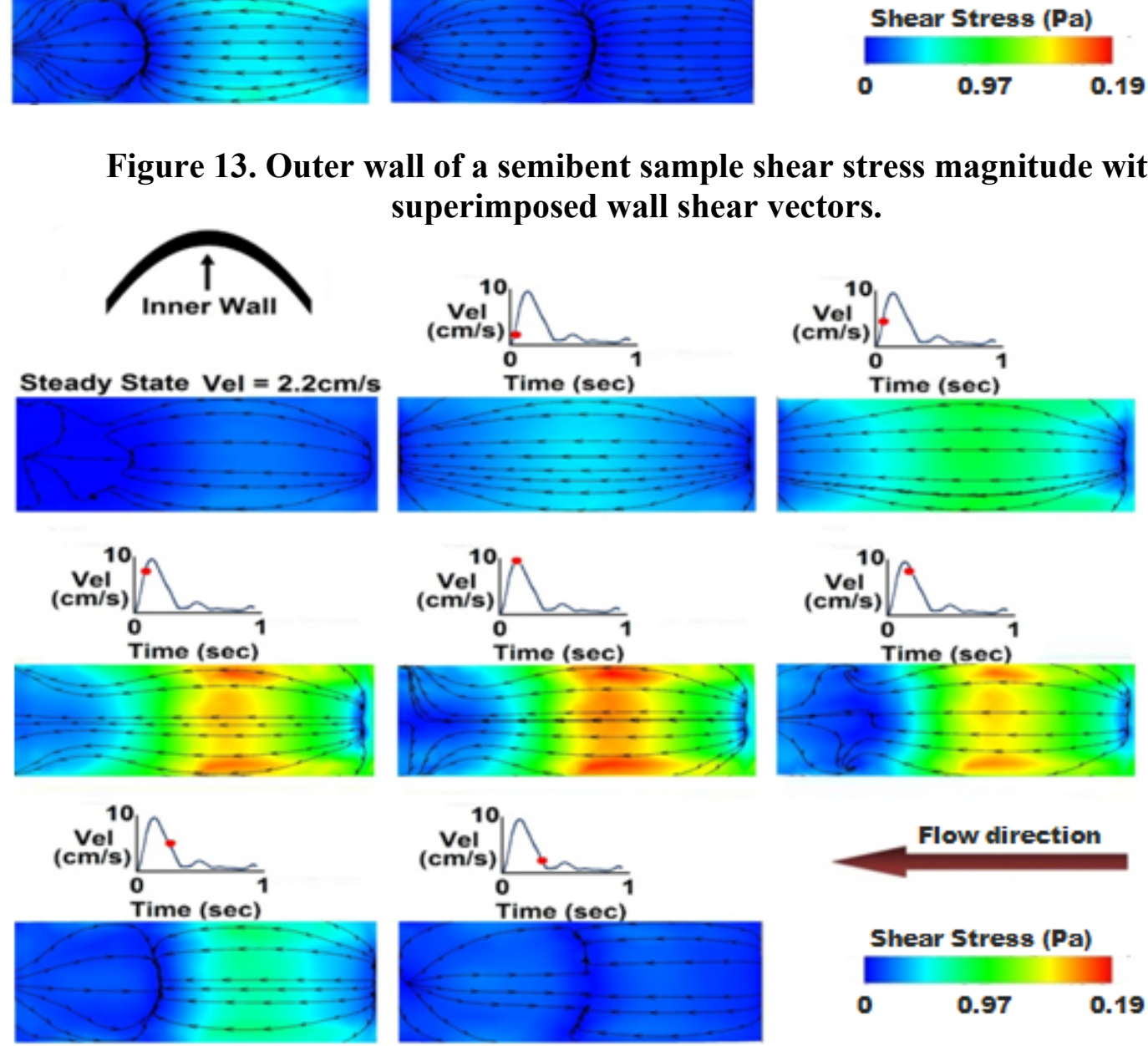

Figure 14. Inner wall of a fully-bent sample shear stress magnitude with superimposed wall shear vectors. 

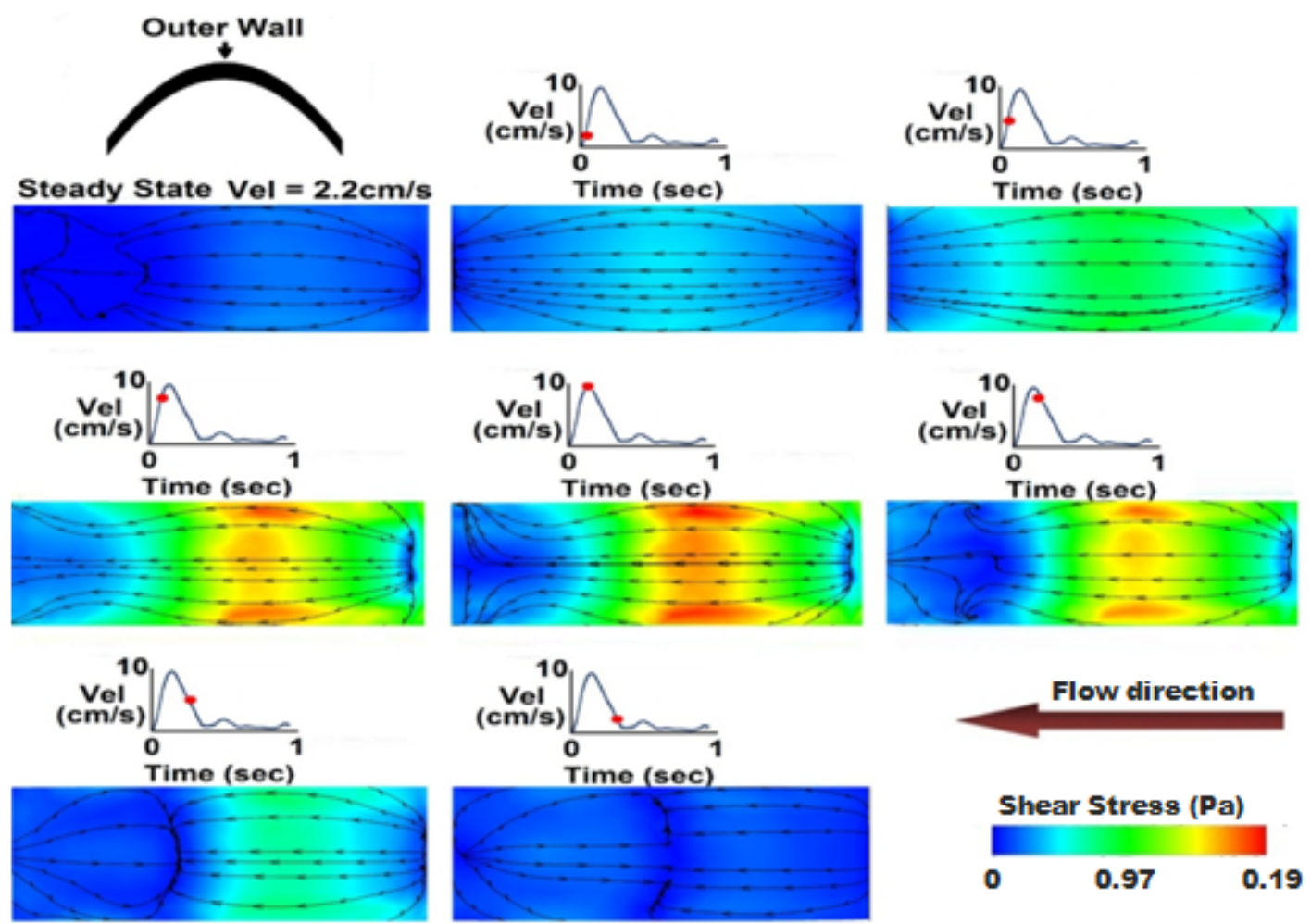

Figure 15. Outer wall of a fullybent sample shear stress magnitude with superimposed wall shear vectors.

In order to observe the role that velocity acceleration and deceleration had on the direction of shear stress streamlines, an instantaneous velocity of $2.2 \mathrm{~cm} / \mathrm{s}$ for both phases of acceleration was used. This is also the velocity that was used as the inlet condition for the steady state simulations. Specimen friction streamlines were found to be in the fully forward direction under steady flow and during the acceleration phase of the pulsatile flow waveform (Fig. 16). On the other hand, complete flow reversal was observed during the deceleration phase on both the inner and outer walls of the 
specimens.

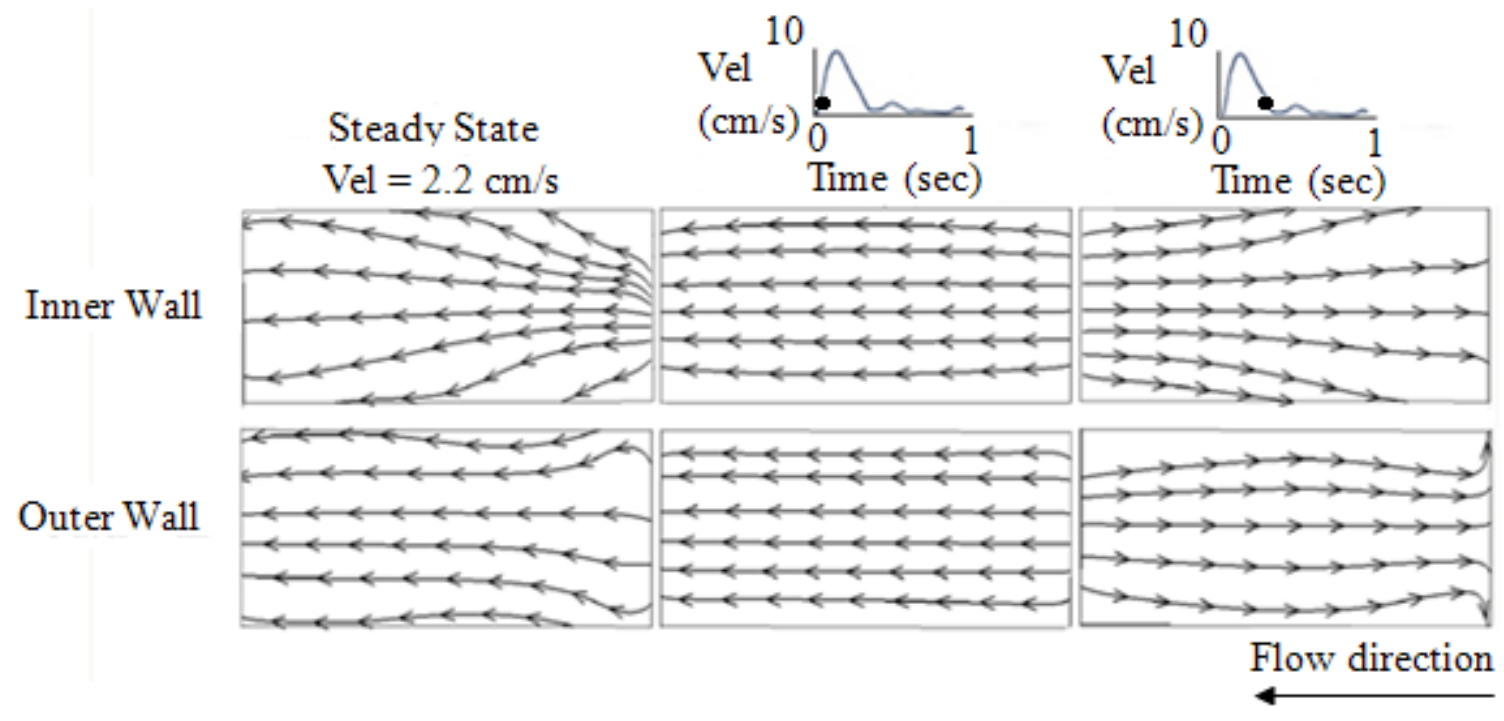

Figure 16. Shear stress streamlines on the outer and inner walls of a straight sample under steady $(\mathrm{vel}=0.022 \mathrm{~m} / \mathrm{s})$ and pulsatile conditions.

Observations on the axial shear stress profiles for three sample configurations simulated under steady profiles was done (Fig. 17). Shear stress vectors show the direction of the flow when the sample was in a straight configuration. Shear stress vectors did not follow the direction of the flow when the sample was semi or fully-bent. This observation can be seen more clearly in the inner walls of the samples. 

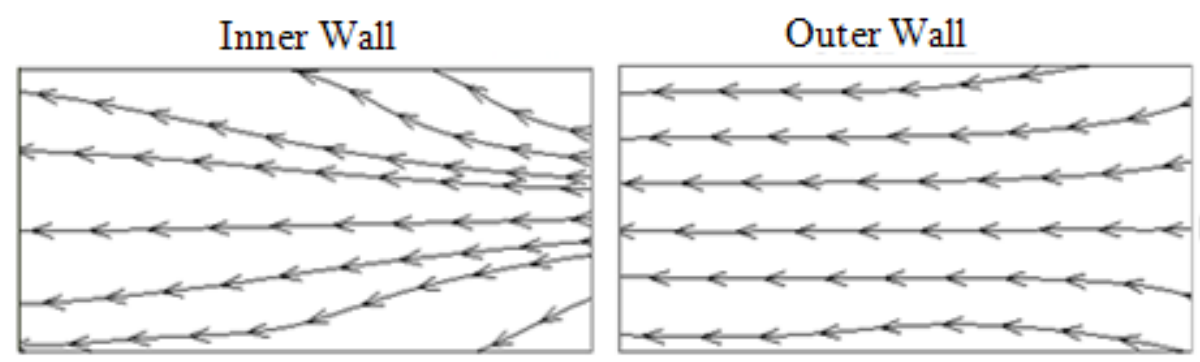

Flow direction
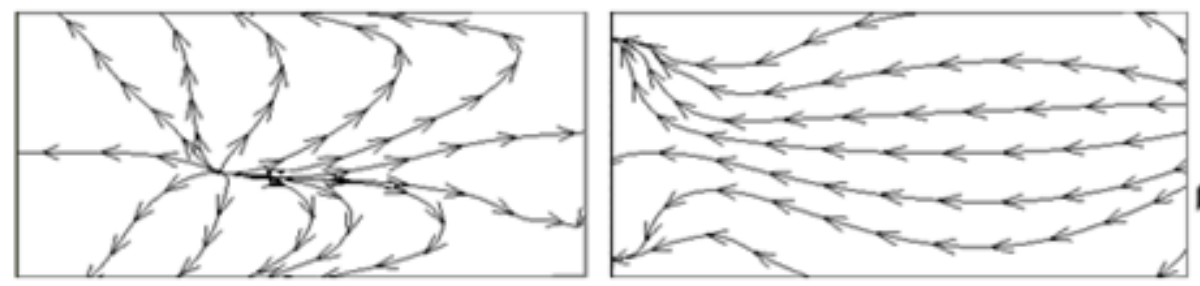

Flow direction
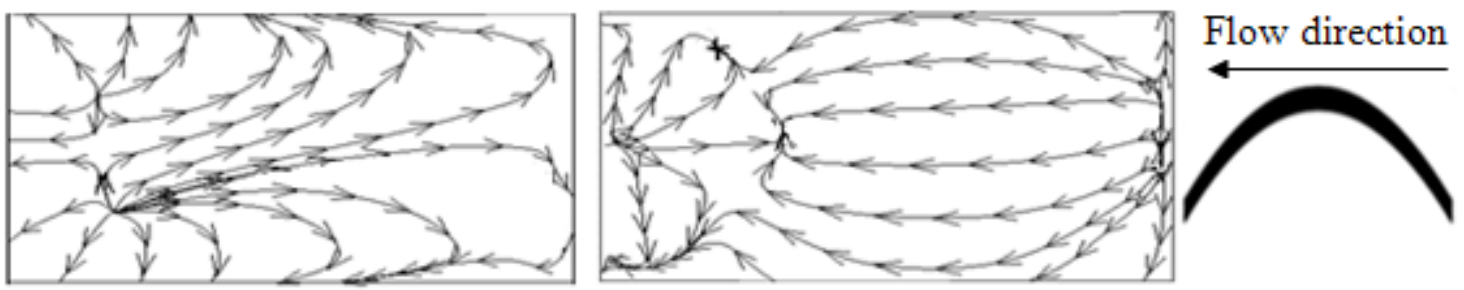

Figure 17. Axial shear stress (Flow direction) streamlines on the outer and inner walls of a straight sample in steady state cases $(\mathrm{vel}=2.2 \mathrm{~cm} / \mathrm{s})$.

Figures 18 and 19 show the axial shear stress at different instantaneous waveform velocities with straight sample positions. The vectors follow the direction of the flow in the inner wall. There was a slight change in the direction of the vectors at the last instantaneous velocity of the deceleration phase in the outer wall (Fig 19). Axial shear stress magnitude increased with increasing velocity (Fig 20, 21). 
$\uparrow$

Inner Wall

Steady State Vel $=2.2 \mathrm{~cm} / \mathrm{s}$

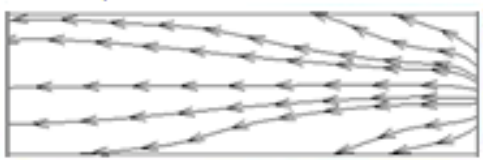

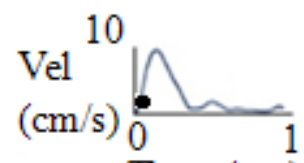

Time (sec)

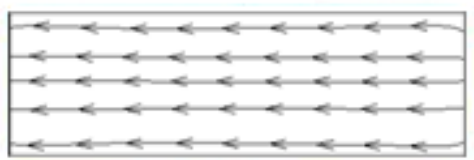

$(\mathrm{cm} / \mathrm{s})_{0}^{10}$

Time (sec)

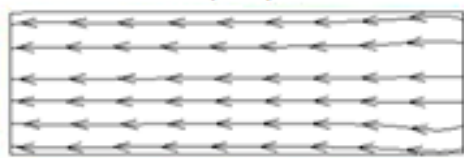

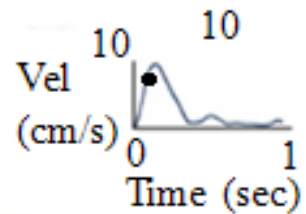

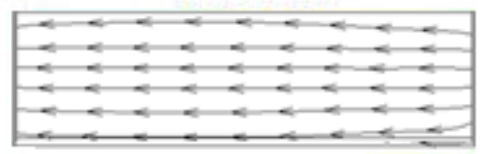

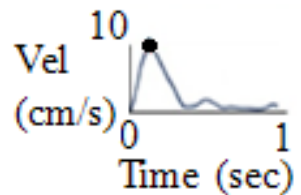

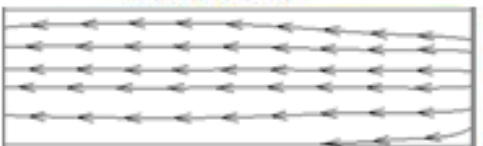

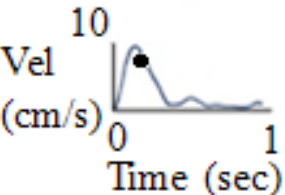

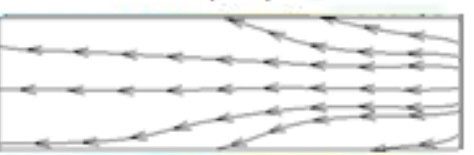

Flow direction

Figure 18. Inner wall of a straight sample with superimposed axial (Flow-direction) shear stress vectors at steady and instantaneous velocities.

Outer Wall

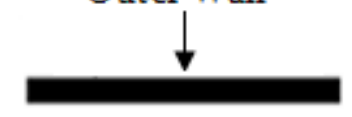

Steady State Vel $=2.2 \mathrm{~cm} / \mathrm{s}$

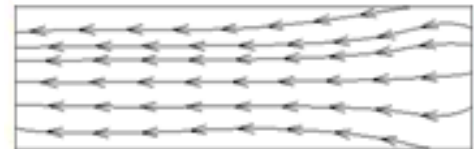

10
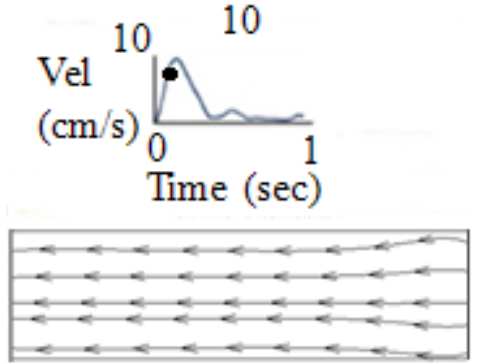

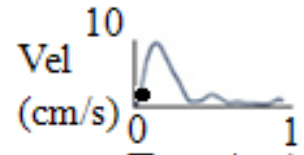

Time (sec)
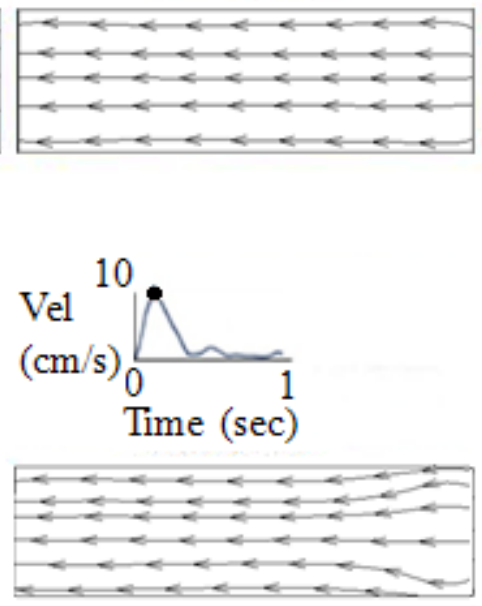

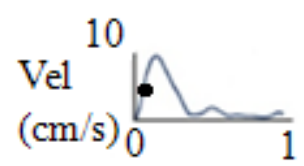

Time (sec)
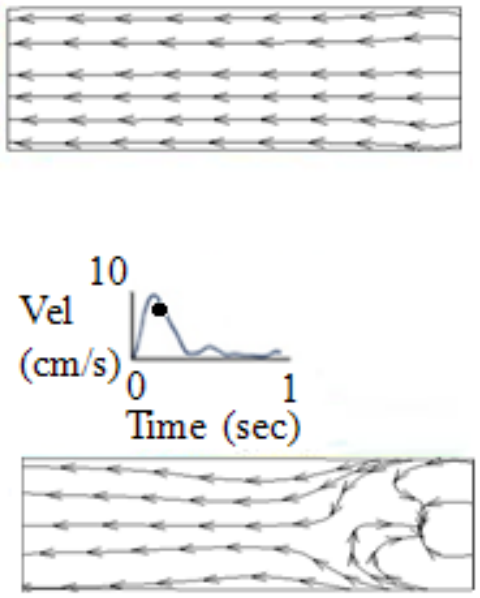

Flow direction

Figure 19. Outer wall of a straight sample with superimposed axial (Flow-direction) shear stress vectors at steady and instantaneous velocities. 


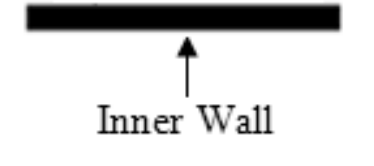

Steady State Vel $=2.2 \mathrm{~cm} / \mathrm{s}$
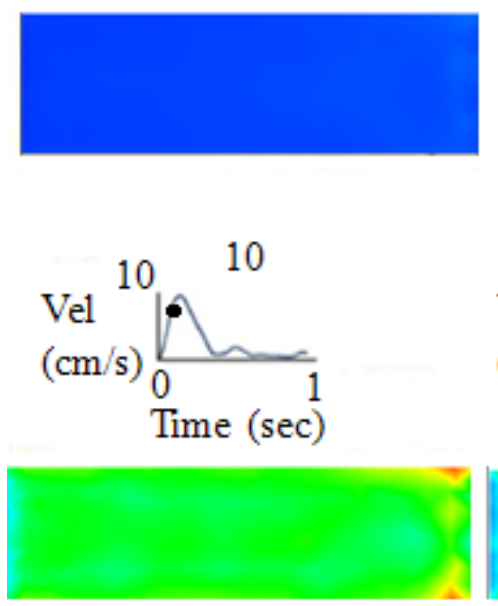
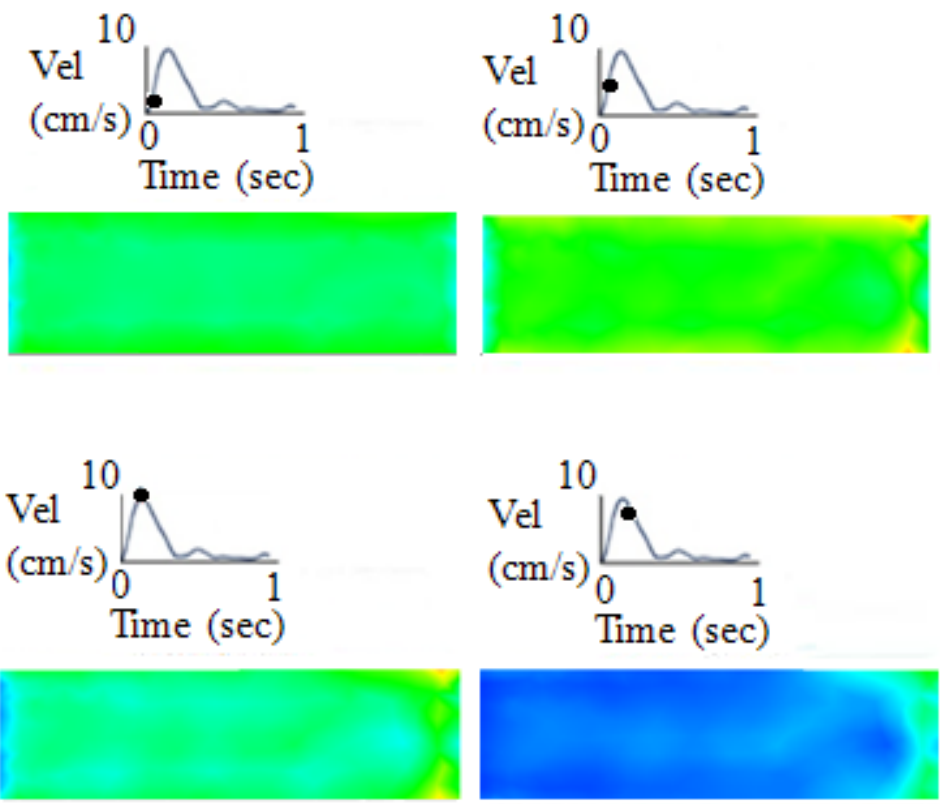

Axial Shear Stress (Pa)

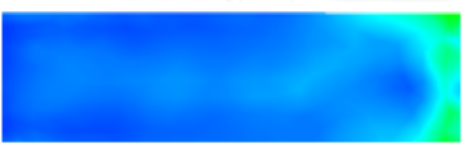

Flow direction

\section{$\begin{array}{lll}-0.06 & 0.61 & 0.12\end{array}$}

Figure 20. Inner wall of a straight sample showing axial shear stress magnitude at steady and instantaneous velocities.

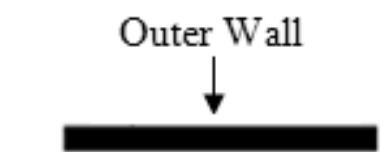

Steady State Vel $=2.2 \mathrm{~cm} / \mathrm{s}$
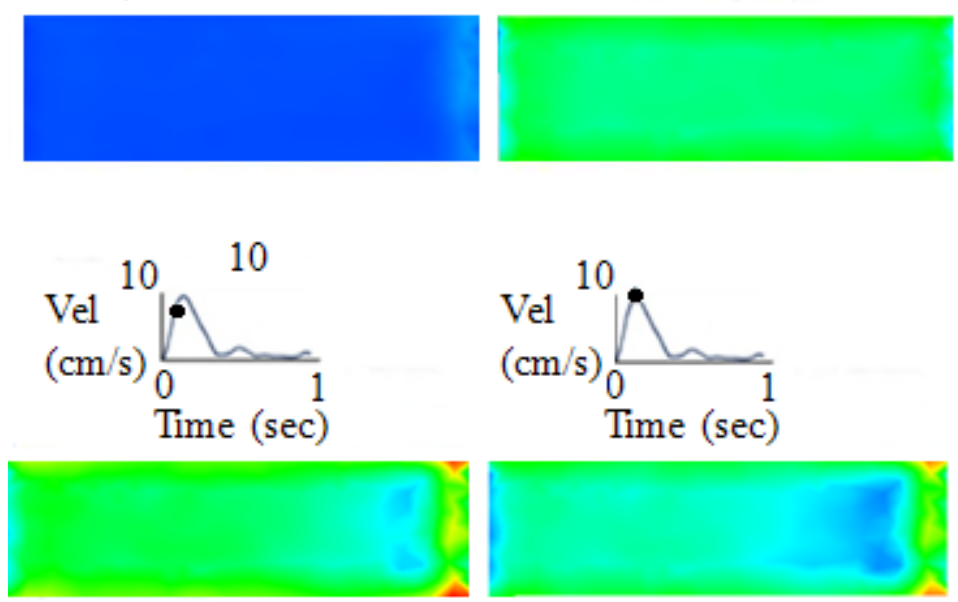

Axial Shear Stress (Pa)

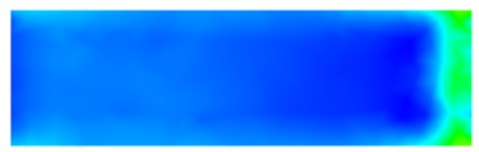

$\begin{array}{lll}-0.06 & 0.61 & 0.12\end{array}$
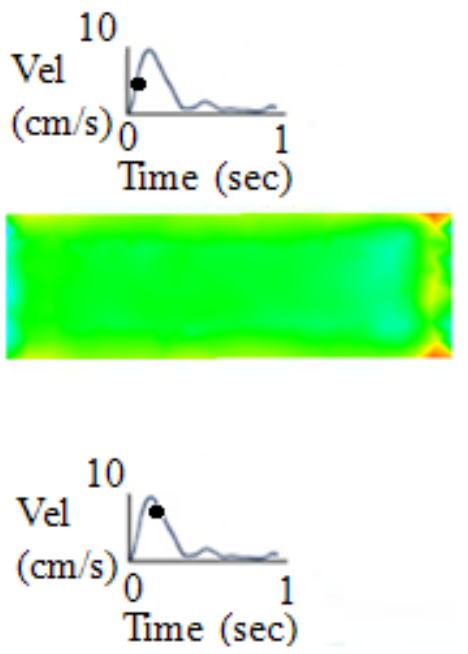

Flow direction

Figure 21. Outer wall of a straight sample showing axial shear stress magnitude at steady and instantaneous velocities. 
OSI variability was highest along the inner and outer walls $(\mathrm{N}=3$ specimens $)$ in the quasi static case (Fig.22). On the other hand, OSI variability was lowest along the inner and outer walls of straight samples $(\mathrm{N}=3)$ subjected to pulsatile flow. OSI distribution was highest along both the inner and outer walls when specimens $(\mathrm{N}=3)$ were held fixed in a straight configuration (average specimen OSI $=0.26$, inner wall; average specimen OSI $=0.27$, outer wall) and subjected to a physiologically-relevant pulsatile flow field (Fig.23). From the quasi-static analysis, when the flow was steady, the OSI reduced by $\sim 62 \%$ on the inner wall and $\sim 8 \%$ on the outer wall. Finally, when the specimen configuration was fixed in a bent-state, the OSI decreased in comparison to the straight specimens under pulsatile flow conditions (Fig.23). In addition, OSI was plotted along the centerline of one sample (Fig. $24 \& 25$ ).

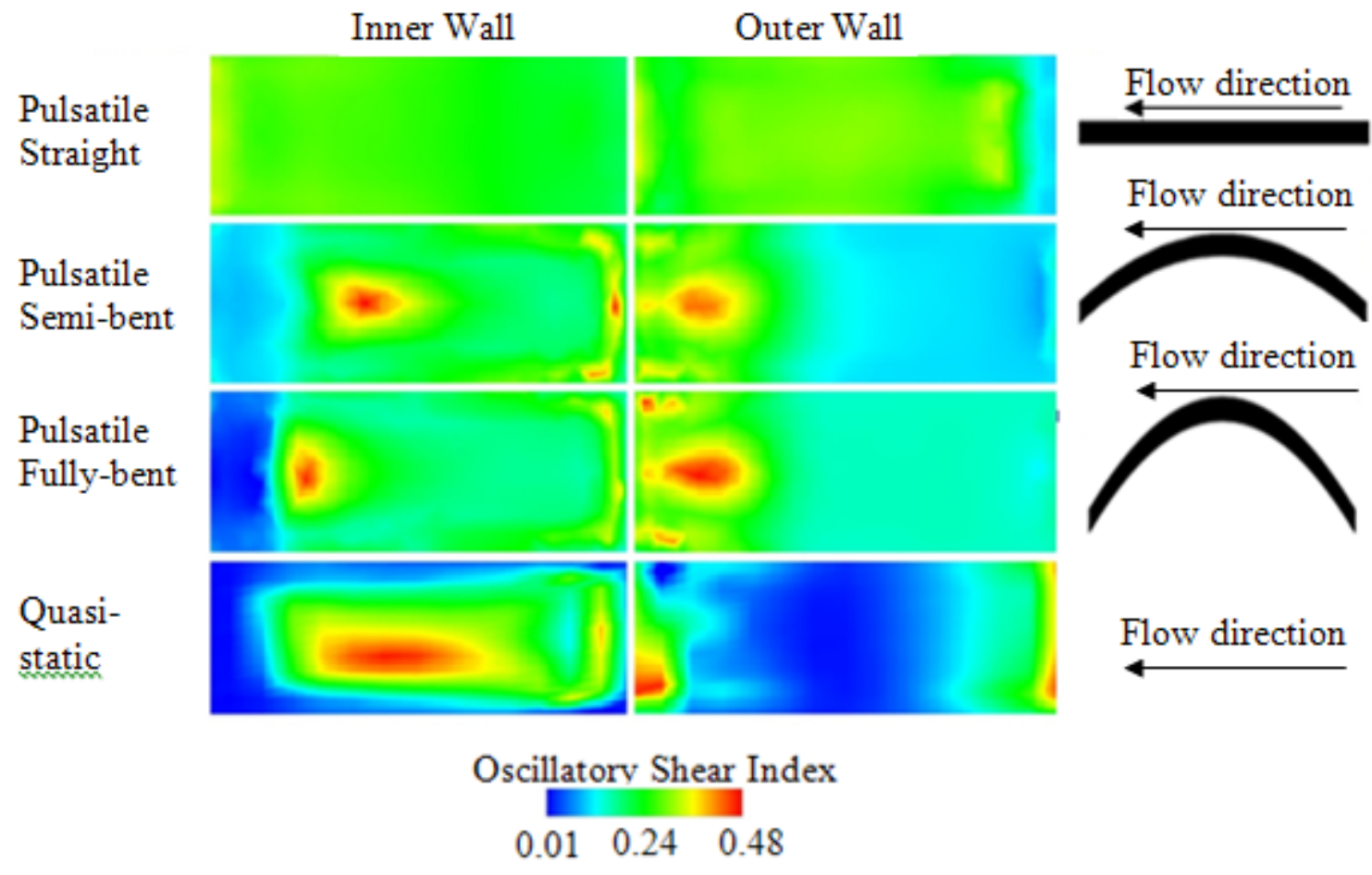

Figure 22. Oscillatory shear index contour for the inner $(n=3)$ and outer walls $(n=3)$. It shows four cases: straight pulsatile, semi-bent pulsatile, fully-bent pulsatile and quasi-static. 
Average OSI for Inner and Outer Walls

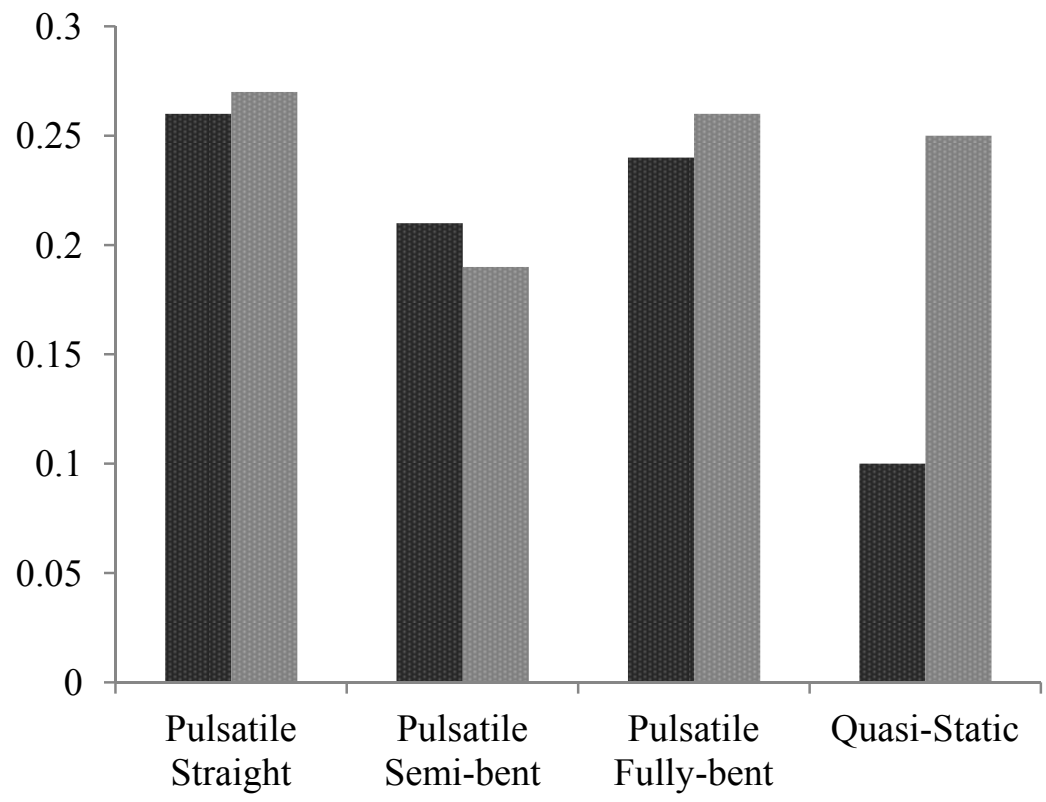

Inner Wall

in Outer Wall

Figure 23. Bar chart showing OSI.

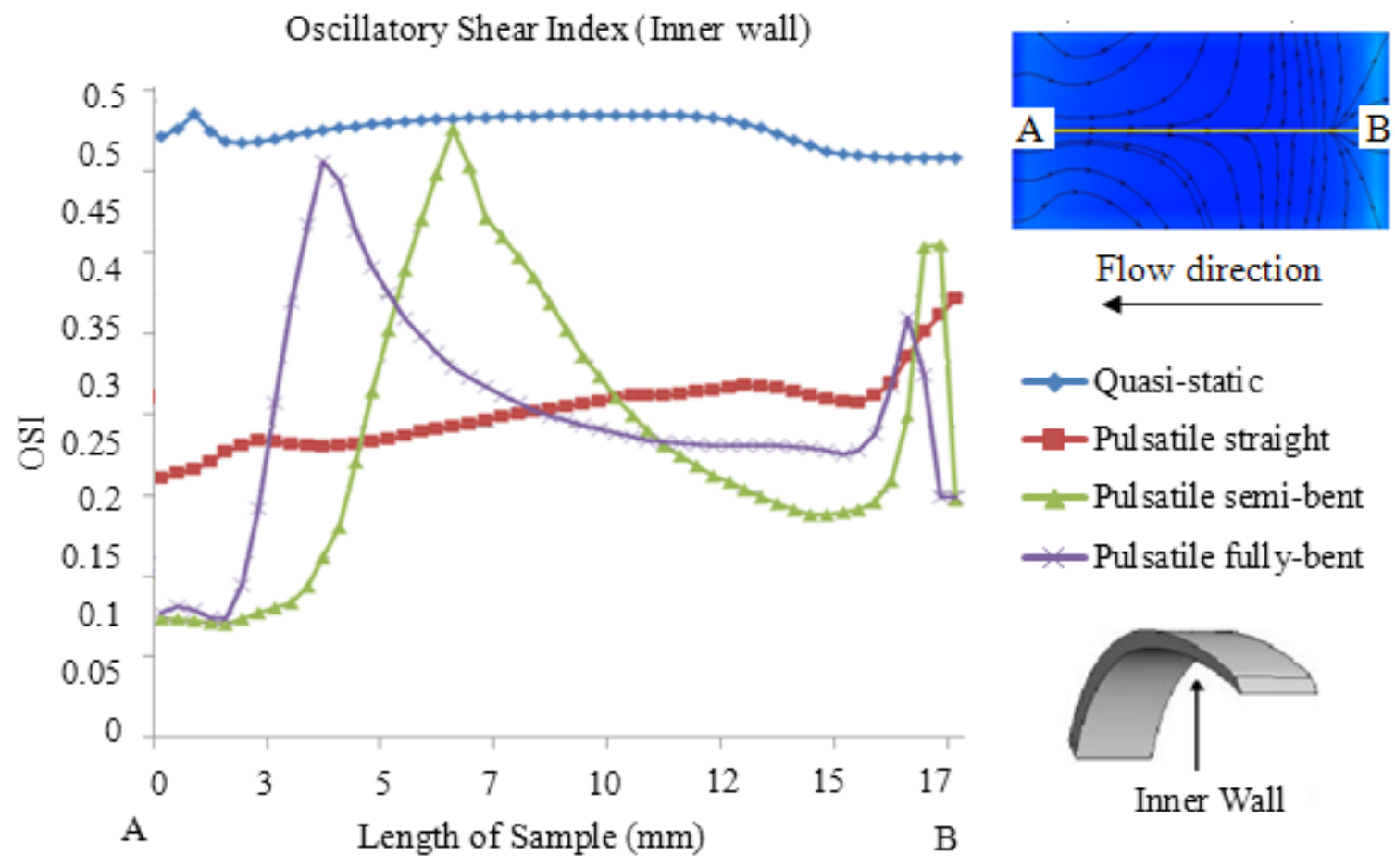

Figure 24. Inner wall OSI distribution along the centerline of samples. 


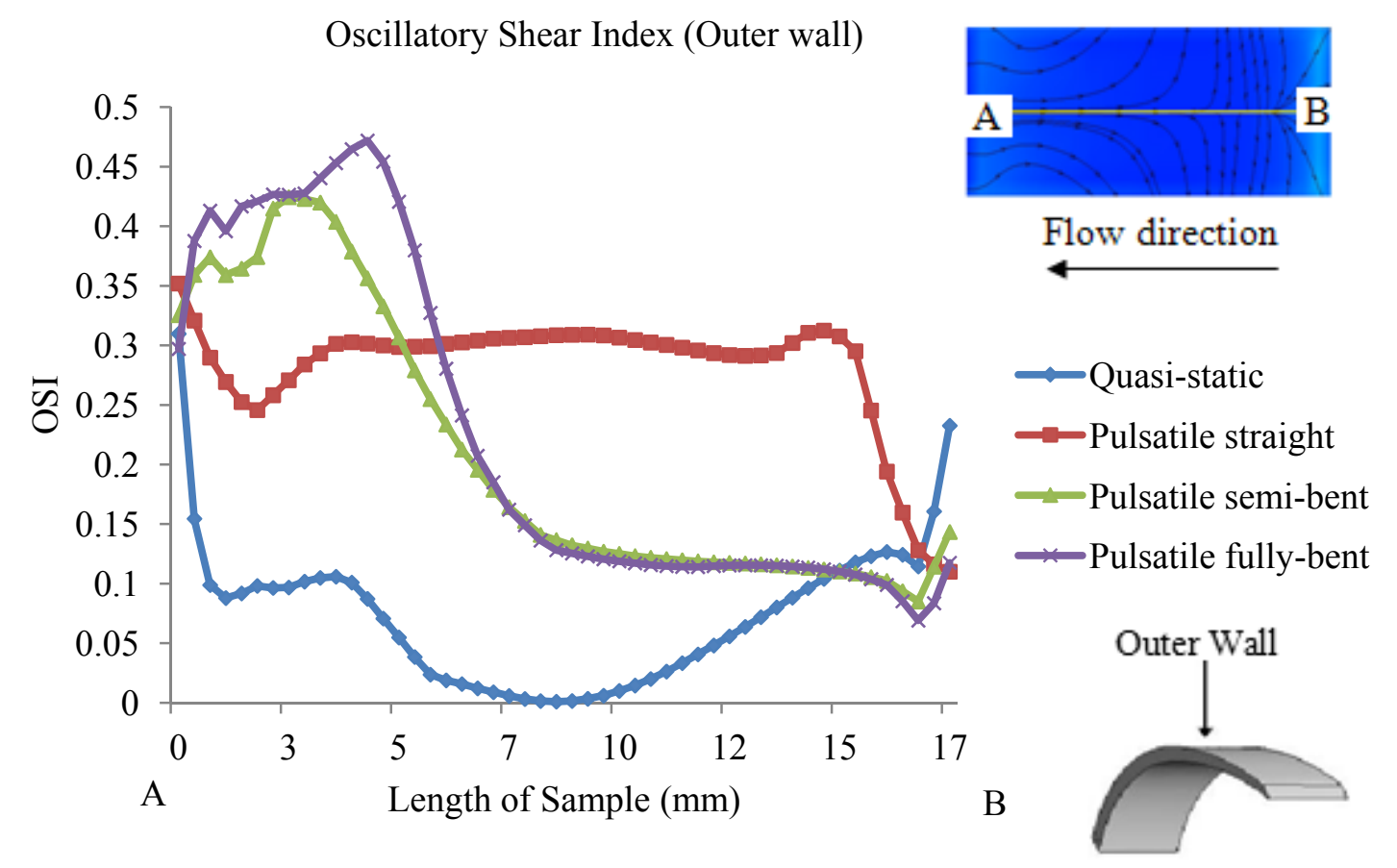

Figure 25. Outer wall OSI distribution along the centerline of samples.

Observations for velocity in the steady cases were conducted by using a centerline through the upper chamber of the bioreactor as shown on figure 26a. Initial observations on the lower chamber did not show significant velocity changes. Regions of velocity absence was observed for the semi-bent and fully bent geometries. This was due to higher sample flexures that intersected and surpassed the centerline of the chamber (Fig. 26b). Interestingly, the velocity increased as it approached the sample location and it further augmented as it encountered the second and third sample. The velocity closer to the outlet was higher that the velocity at the start of the chamber. This suggests that the presence of the sample created a narrowing in the total cross sectional area of the chamber and it resulted in observed velocity intensification. 

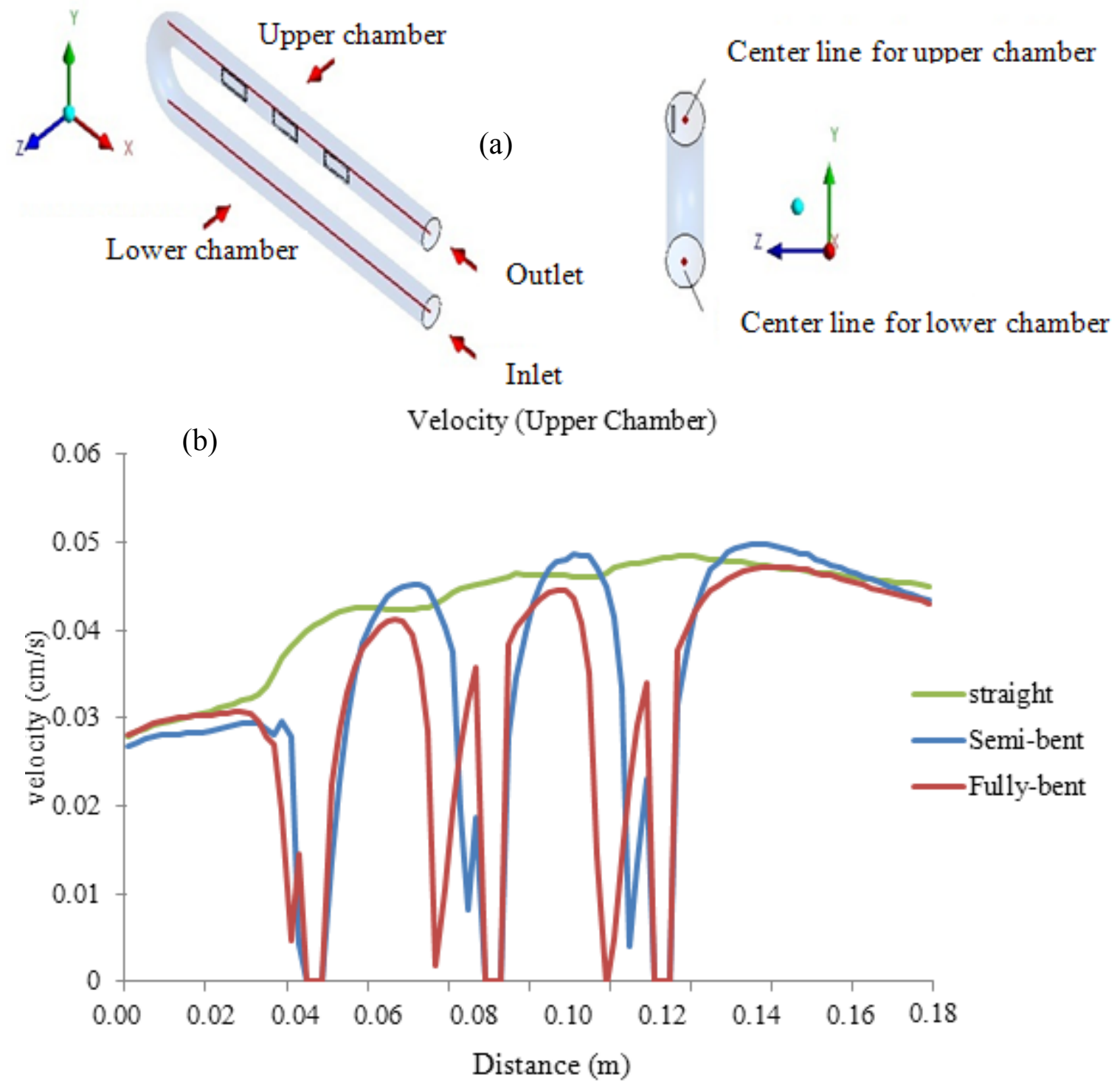

Figure 26. (a) Centerline showing the upper and lower chamber of the u-shaped bioreactor (b) Steady state velocity at the upper chamber centerline for three sample configurations.

In order to have a better understanding of the velocity profile found in straight samples subjected to pulsatility, the velocity at the center line of the upper chamber (Fig. 26a) at specific time intervals was plotted. Specifically, these observations were done at $0.1 \mathrm{sec}$ (Fig. 27), $0.13 \mathrm{sec}$ (Fig. 28), $0.15 \mathrm{sec}$ (Fig. 29), and $0.2 \mathrm{sec}$ (Fig. 30). The time t 
$=0.13 \mathrm{sec}$, corresponds to the highest velocity value $(8.9 \mathrm{~cm} / \mathrm{s})$ from the waveform and shows higher velocity magnitudes over the other time points (Fig. 28). Interestingly, the velocity at the $x=0 \mathrm{~m}$ (beginning of the chamber) are remarkably similar to the velocity close to the outlet. In addition, there is an increase in velocity in the proximity of the samples, but it decreases as it passes away from them. Furthermore, these velocity increments are remarkably similar among the centerline regions in proximity with the samples.
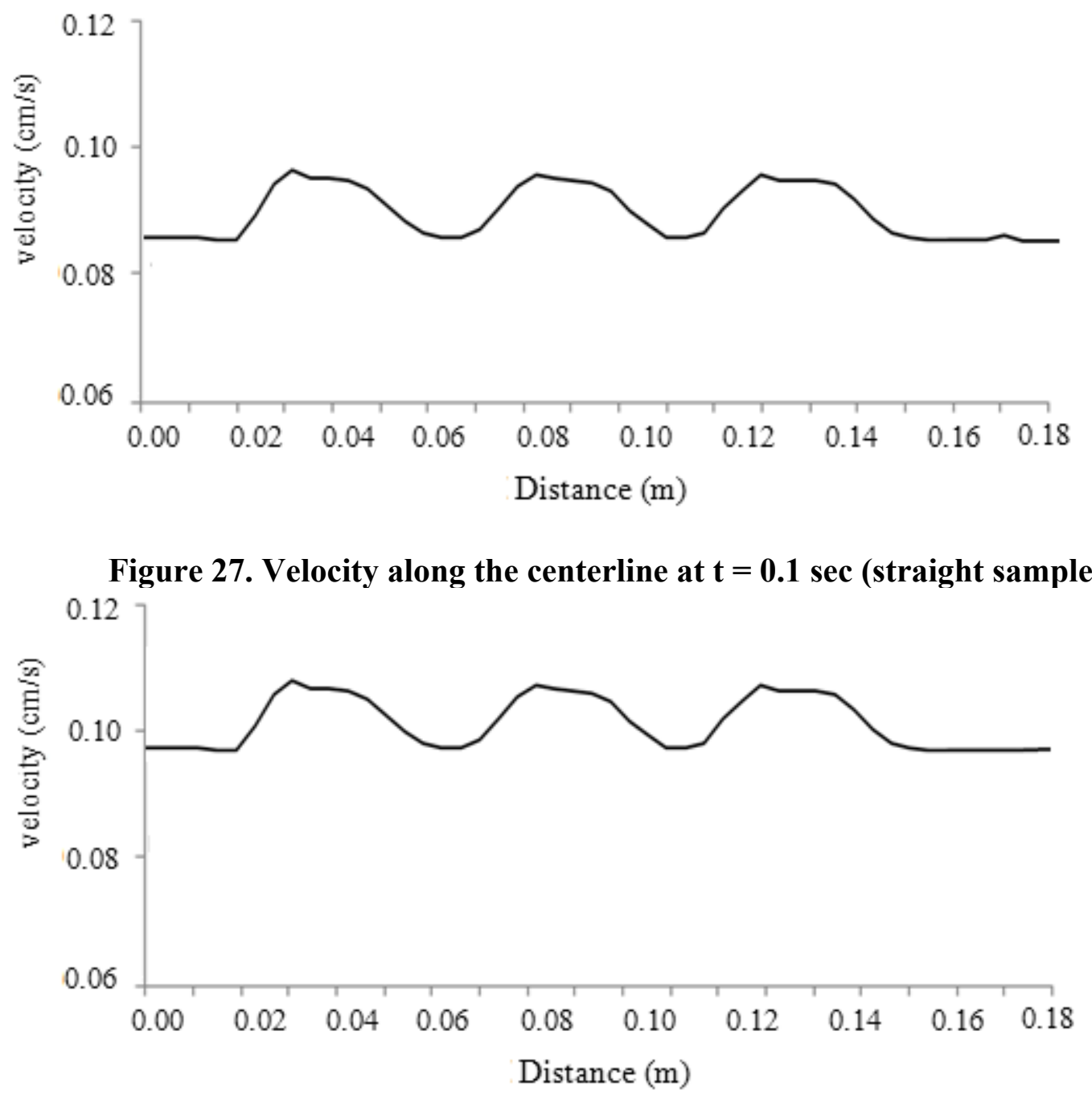

Figure 28. Velocity along the centerline at $t=0.13$ sec (straight samples). 


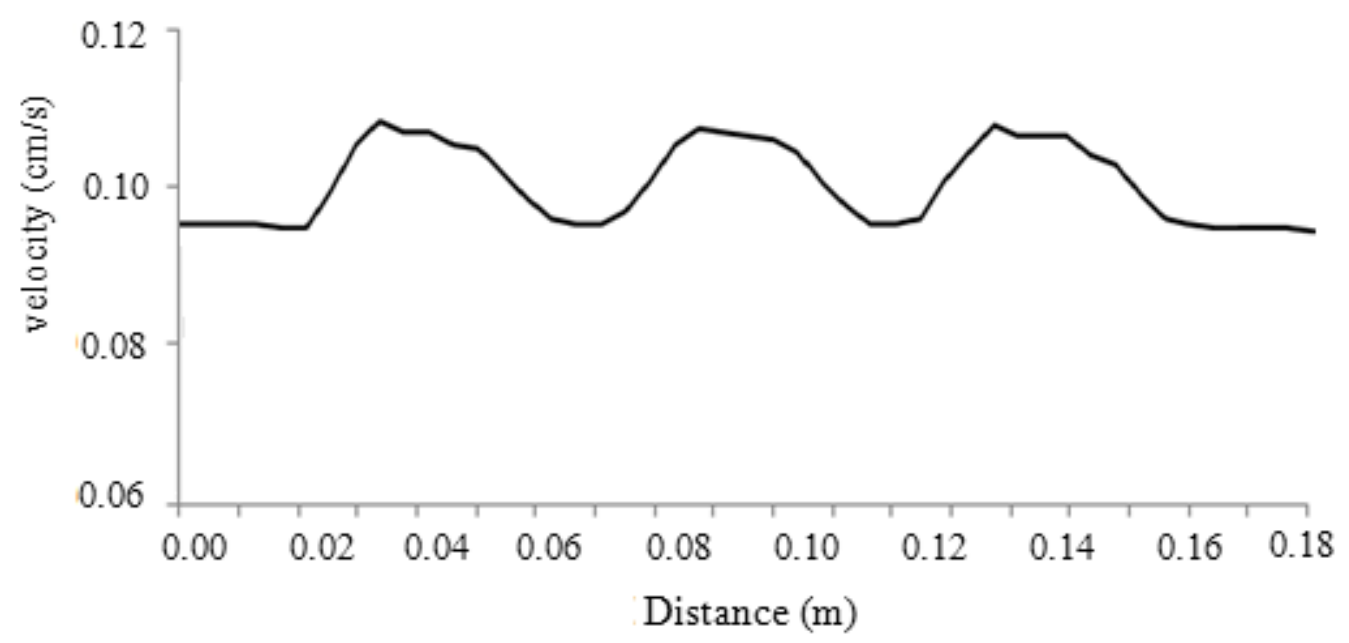

Figure 29. Velocity along the centerline at $\mathrm{t}=\mathbf{0 . 1 5} \mathrm{sec}$ (straight samples).

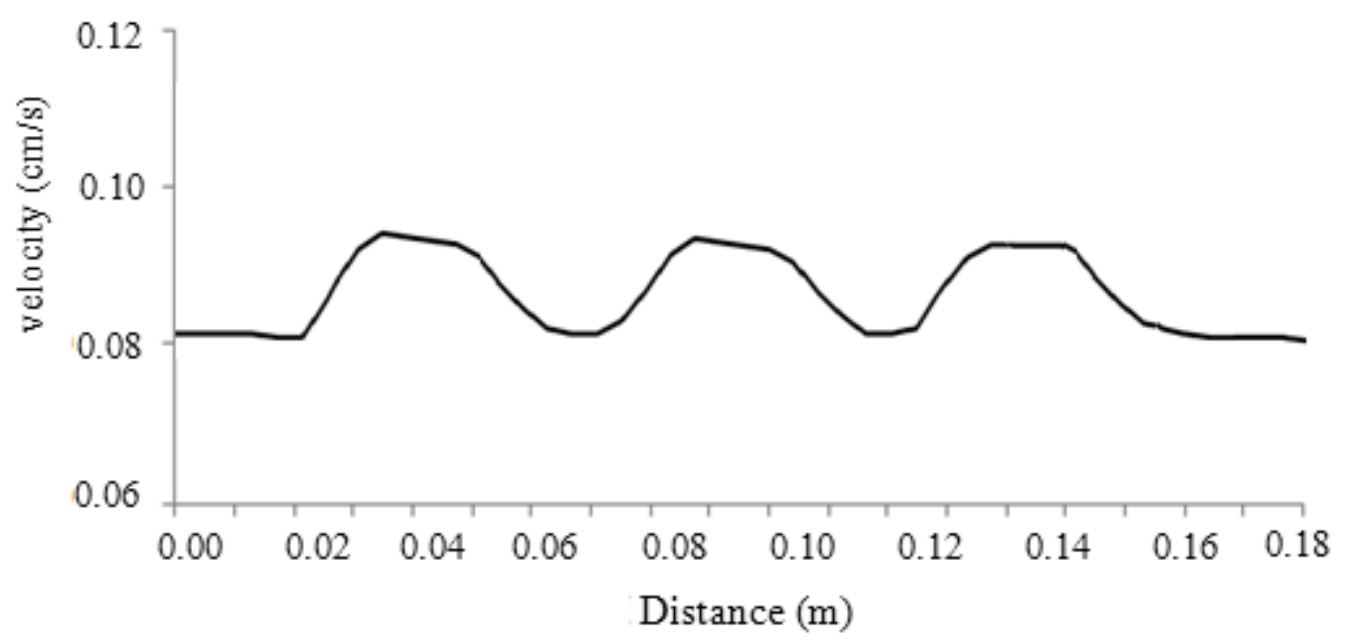

Figure 30. Velocity along the centerline at $\mathrm{t}=0.2 \mathrm{sec}$ (straight samples).

Time averaged vorticity magnitudes along the centerline of the upper chamber were plotted (Fig. 31). Regions of vorticity absence was observed for the semi-bent and fully bent geometries. This was due to higher sample flexures that intersected and surpassed the centerline of the chamber. Similarly, this may have played a role in the quasi-static vorticity quantification due to highly flex samples. Figure 31 reveals areas of very high vorticity magnitude in regions of close proximity to the upstream side of the samples. In the case of the straight configuration, vorticity centerline profiles showed remarkable similarity among samples. Because of this it was decided that a closer look at 
the centerline vorticity of straight samples needed to be performed. The instantaneous vorticity at $\mathrm{t}=0.13 \mathrm{sec}$ corresponding to the highest velocity point $(8.9 \mathrm{~cm} / \mathrm{s})$ was designed (Fig. 32).

Time Averaged Vorticity (Upper Chamber)

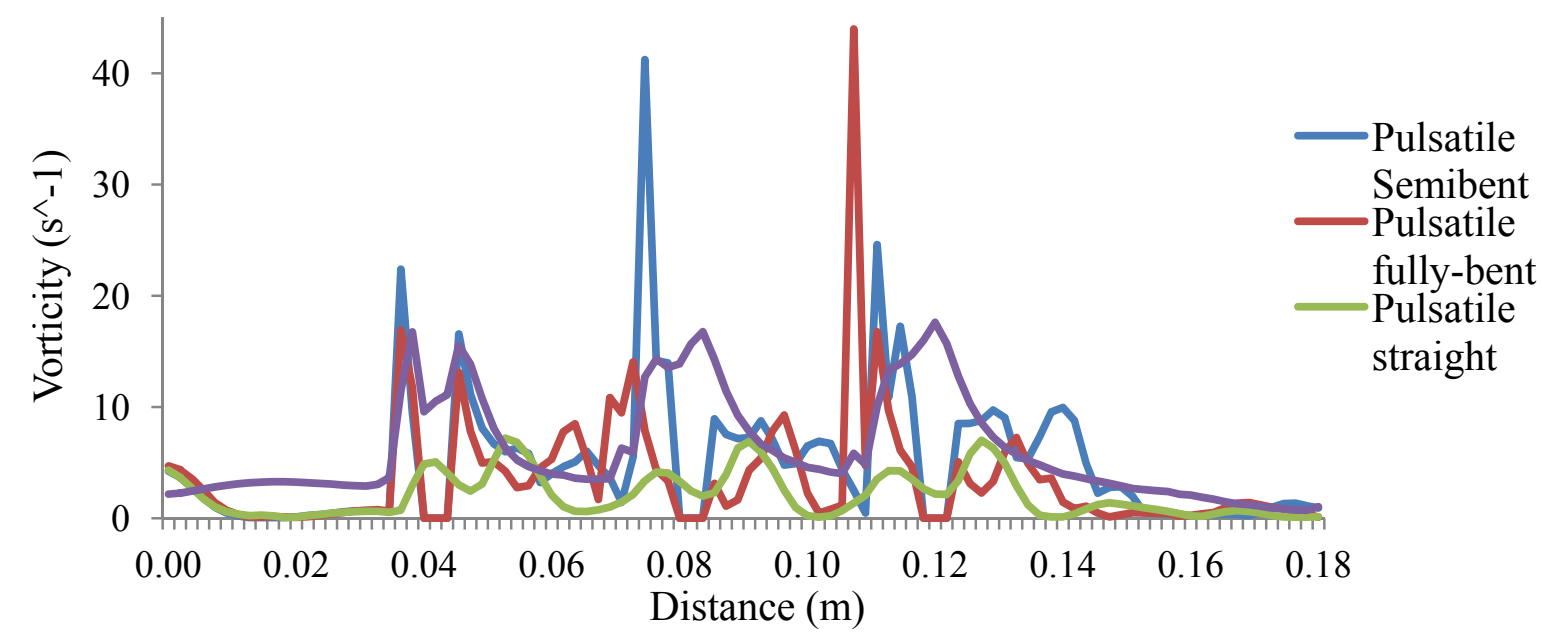

Figure 31. Time average vorticity along the centerline of the upper chamber for pulsatile and quasi-static.

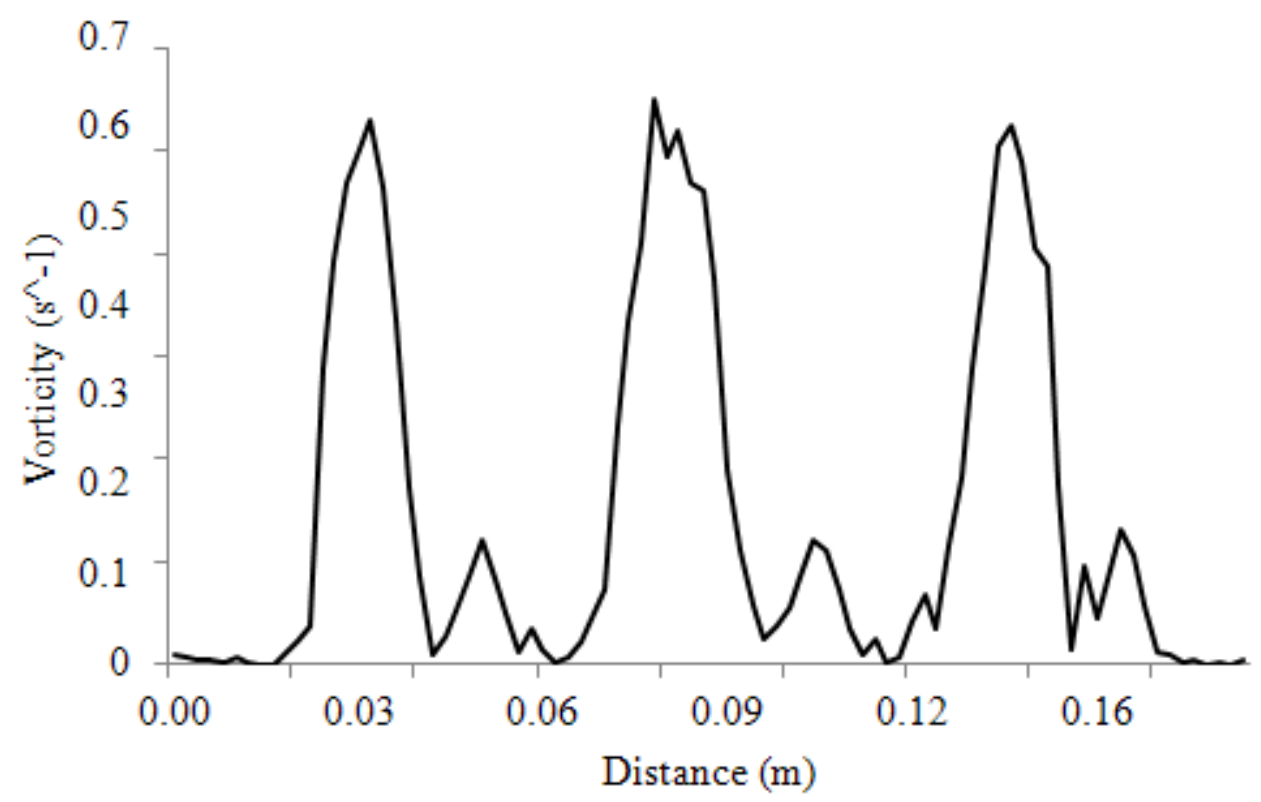

Figure 32. Instantaneous vorticity along the centerline of the upper chamber with straight samples and pulsatile flow. 


\subsection{Discussion}

In cardiovascular tissue engineering, there is widespread agreement that dynamic culture using mechanical conditioning protocols, promotes tissue formation. It is been shown that in-vitro conditioning by means of flow environments enhances engineered tissue formation $[1,7,8]$ and regulate specific transcription factors of progenitor cells that modulate phenotype $[16,54]$. However, the explicit flow criteria for supporting tissue growth, in the context of HVTE efforts have not been sufficiently identified. Thus, there is ambiguity on the precise fluid-induced mechanisms governing the production of de novo valve tissue $[7,8,45]$. Some observations suggest that it is the oscillatory stress environments that are responsible for stimulating tissue development $[7,38]$.

This study investigated and quantified the role that i) specimen configuration and ii) use of a physiologically relevant pulsatile flow waveform have on creating OSS environments. It was found that physiologic OSS environments are maximized when specimens were placed in a fixed, straight configuration and were exposed to a pulsatile waveform [60]. Moreover, this setting comes accompanied with a highly uniform OSS distribution across all samples housed within the bioreactor thereby ensuring minimal variation in engineered tissue formation between specimens.

These findings demonstrate that OSS focused experiments for HVTE does not require a moving component and simplifies the design of a bioreactor for supporting these investigations. However the flow source has to be able to incorporate physiological waveforms and induce pulsatile flow through the conditioning chamber. This can be readily accomplished using a peristaltic pump [8]. [38] reported higher tissue formation under conditions of flow and flexure combined. The quasi-static results suggest that this 
could be partially due to the OSS environments caused by cyclic alteration in the fluid environments due to the deforming sample submerged into the continuous flow. Engelmayer et al. (2006) [16] reported an increase in number of cells and tissue formation in constructs conditioned by means of pulsatile flow over controls (no flow).

The pulsatile simulations over static scaffolds subjected to pulsatile flow regimes suggest that OSS might have played a role in these findings by promoting cell proliferation and tissue formation. Support for this belief can be found in bone tissue engineering studies $[53,62]$. It should be noted that a limitation of this study was that it did not account for fully dynamic states; rather it took a quasi-static approach in considering OSS environments resulting from changing specimen configurations. A true dynamic CFD simulation would require incorporation of fluid-structure or other moving boundary approaches which would require more computational implementation and time, yet unnecessary for the purposes of a primary objective here, which was to reasonably approximate the OSS distributions on the specimens. This was achieved by the quasistatic model, firstly by the use of meshes that accurately depicted varying specimen geometry at snapshot temporal positions. Secondly, the model operated in the laminar range and was prescribed a uniform inlet velocity condition, which would enable any given fluid particle in the conditioning chamber to come into regular, periodic contact with a housed specimen undergoing cyclical flexure, thus having roughly the same shape at that time instant.

Another limitation is that it only considered the singular effect of OSS on tissue formation which is thought to be beneficial $[7,8,63]$. It is however important to note that specimen movement may provide added benefits to tissue formation, by enhancing mass 
transport of nutrients to the growing tissues. Efforts are currently investigating the role of valve-like specimen movement on engineered tissue formation by BMSCs in bioreactor-based experiments that are being conducted in our laboratory. In summary, this report has shown that OSS can be maximized by inducing pulsatile flow over straight scaffolds. There is strong evidence to believe that OSS promotes BMSCs tissue formation.

\section{RESULTS AND DISCUSSION FOR AIM 3}

HVTE studies have shown that pulsatile environments can promote cell proliferation and tissue formation. This study has shown, through CFD analysis, that during pulsatility there are high areas of OSS acting on the surface of rectangular specimens. In addition, these environments can be maximized by conforming to a straight sample configuration. As a next step, efforts to performed in-vitro studies of BMSCs cultured under no flow and steady flow regimens are underway.

Initially, $\Delta \mathrm{Ct}$ values were averaged and were subsequently normalized with GAPDH. Statistical t-tests were performed over the $2-\Delta \mathrm{Ct}$ values for comparison among no flow and steady flow groups. The results showed an increase in the number of cells attached to the walls of the micro channel with increasing culture time (Fig. 33). The effect of flow compared to no flow on BMSCs was significantly different $(\mathrm{P}<0.05)$. Specifically, significant differences were observed on B-1-INT, PECAM-1, and VECADHERIN (Fig. 34). B-1-INT is associated with extracellular matrix formation (i.e Collagen) [1].

PECAM-1 is an adhesion molecule expressed by vascular ECs [46]. VECADHERIN is important in supporting the EC phenotype and has a critical role in vascular development [58]. 


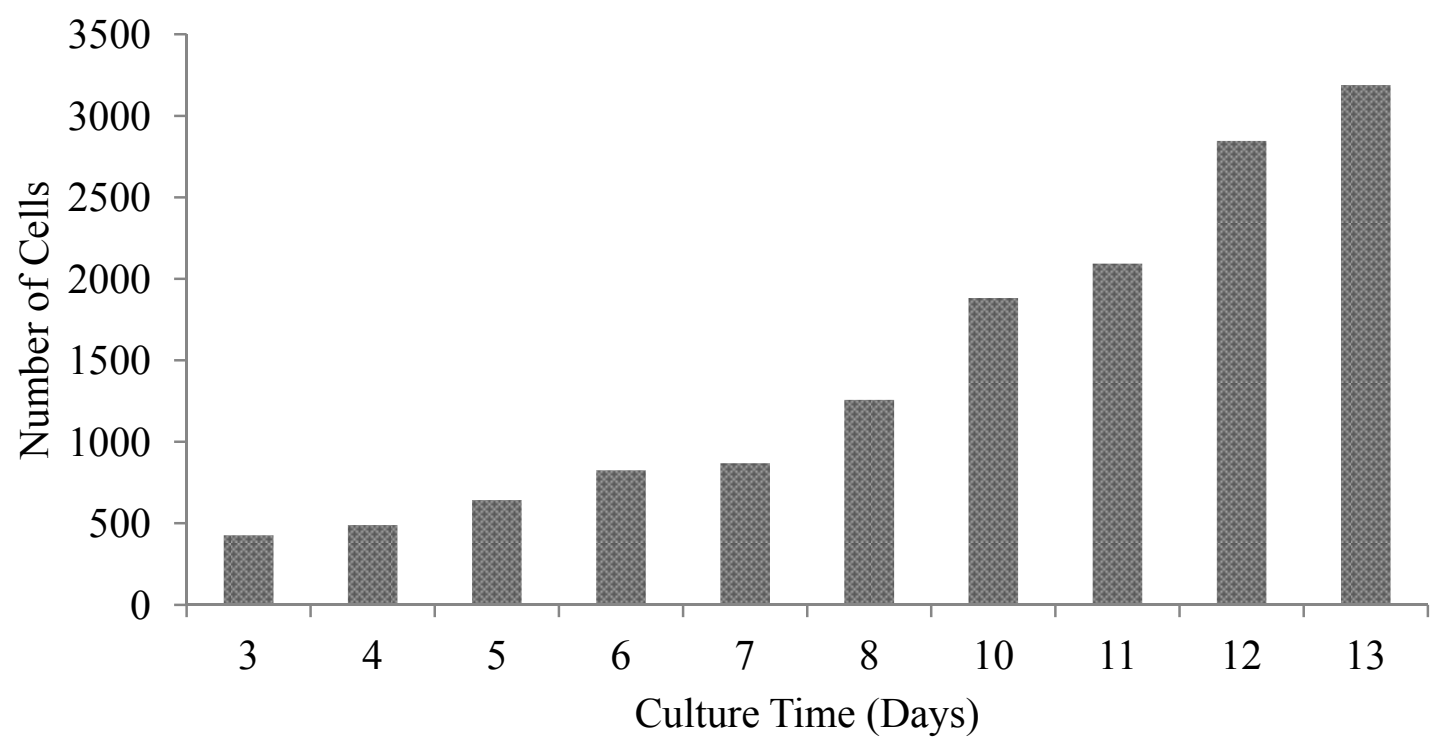

Figure 33. Bar chart showing the number of cells per day during the steady flow experiment.

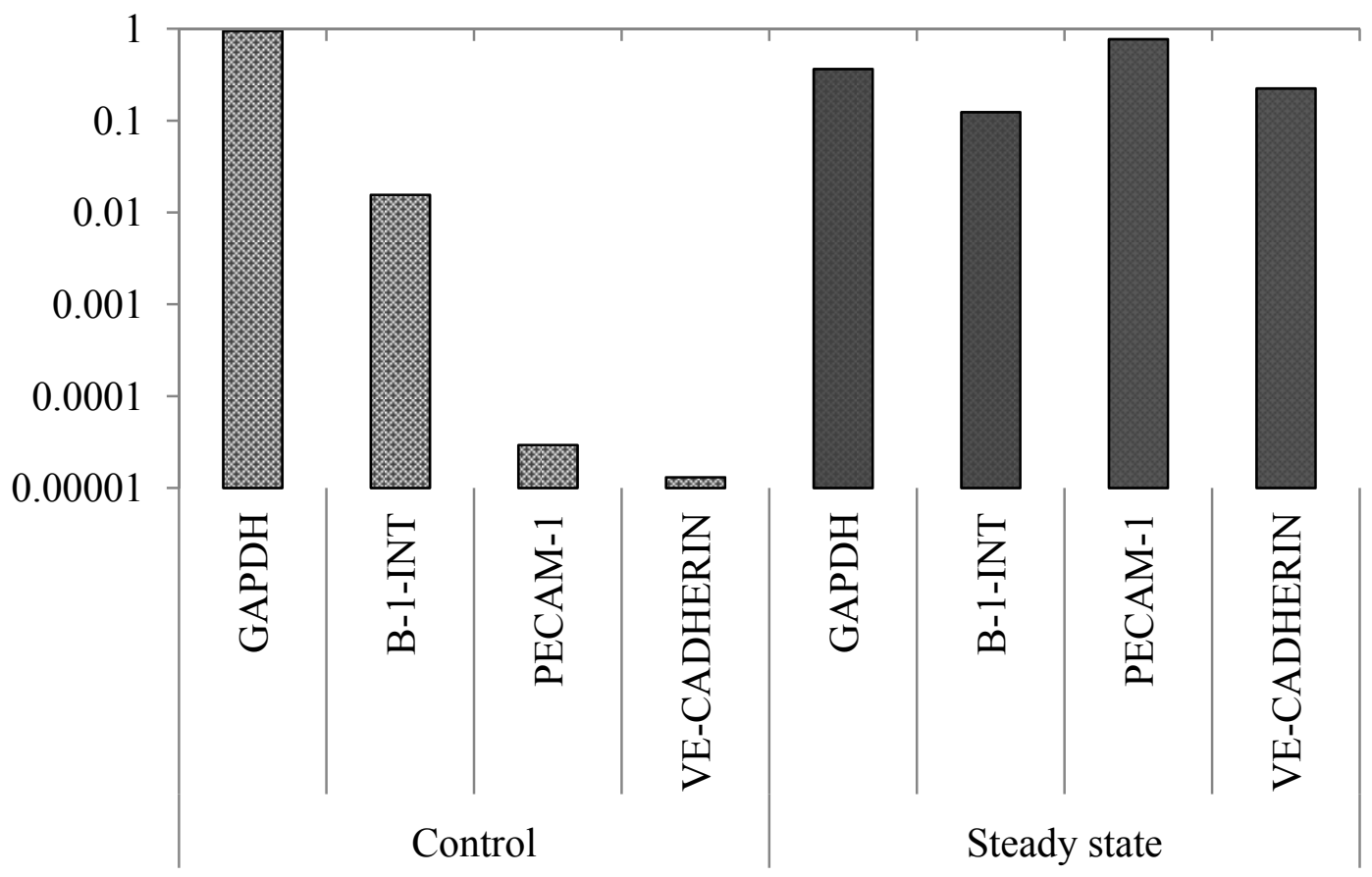

Figure 34. Bar chart showing the genes expressed after no flow and steady flow conditions. 
Pulsatile in-vitro experiments are currently in progress and will provide with quantitative data to assertively delineate any cell proliferation and phenotypic differences between steady and pulsatile flow conditions. In addition, in subsequent in-vitro experiments, evaluation of tissue formation will be performed. Nonetheless, it can be concluded that steady flow alone promotes cell proliferation and phenotypic differentiation.

The quasi-static results showed that OSS environments can be caused by means of cyclic sample flexure. Previous in-vitro experimental data obtained from samples cultured under cyclic flexure combined with flow conditions show higher tissue formation over controls of flow or cyclic flexure alone (Fig. 35). In addition, flex and flow combined groups showed higher elastic modulus than the other groups.

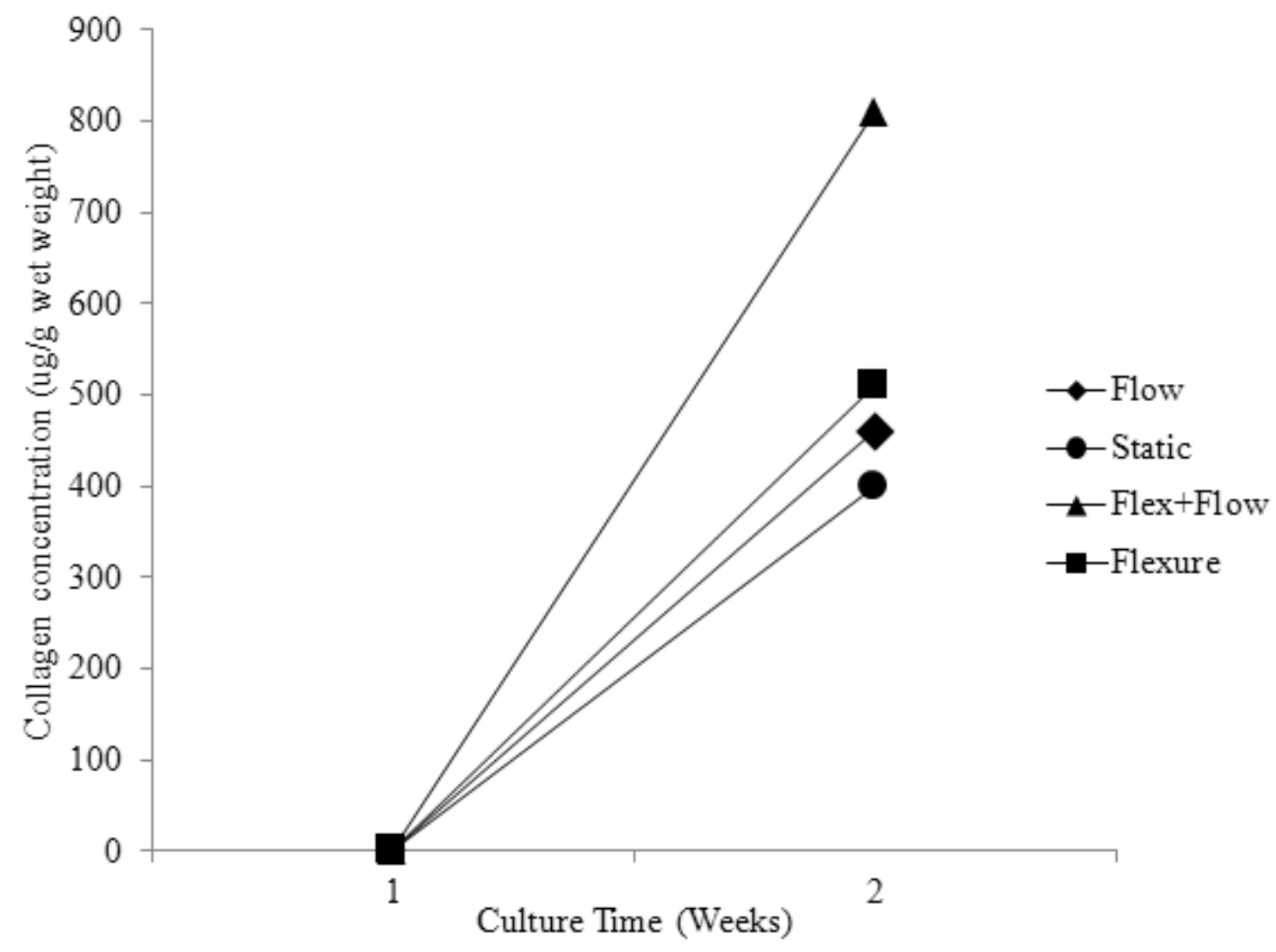

Figure 35. Collagen assay results for BMSC-seeded 50:50 PGA/PLLA scaffolds [38]. 
Similarly, Ramaswamy et al. [7] reported increase in tissue formation in scaffolds seeded with BMSCs and conditioned by means of dynamic sample movement. They used a native valve-like (organ level) geometries and rectangular scaffolds (FSF-level). The organ level constructs subjected to dynamic conditioning had highest collagen production followed by the dynamic regimen of rectangular samples (Fig. 35).

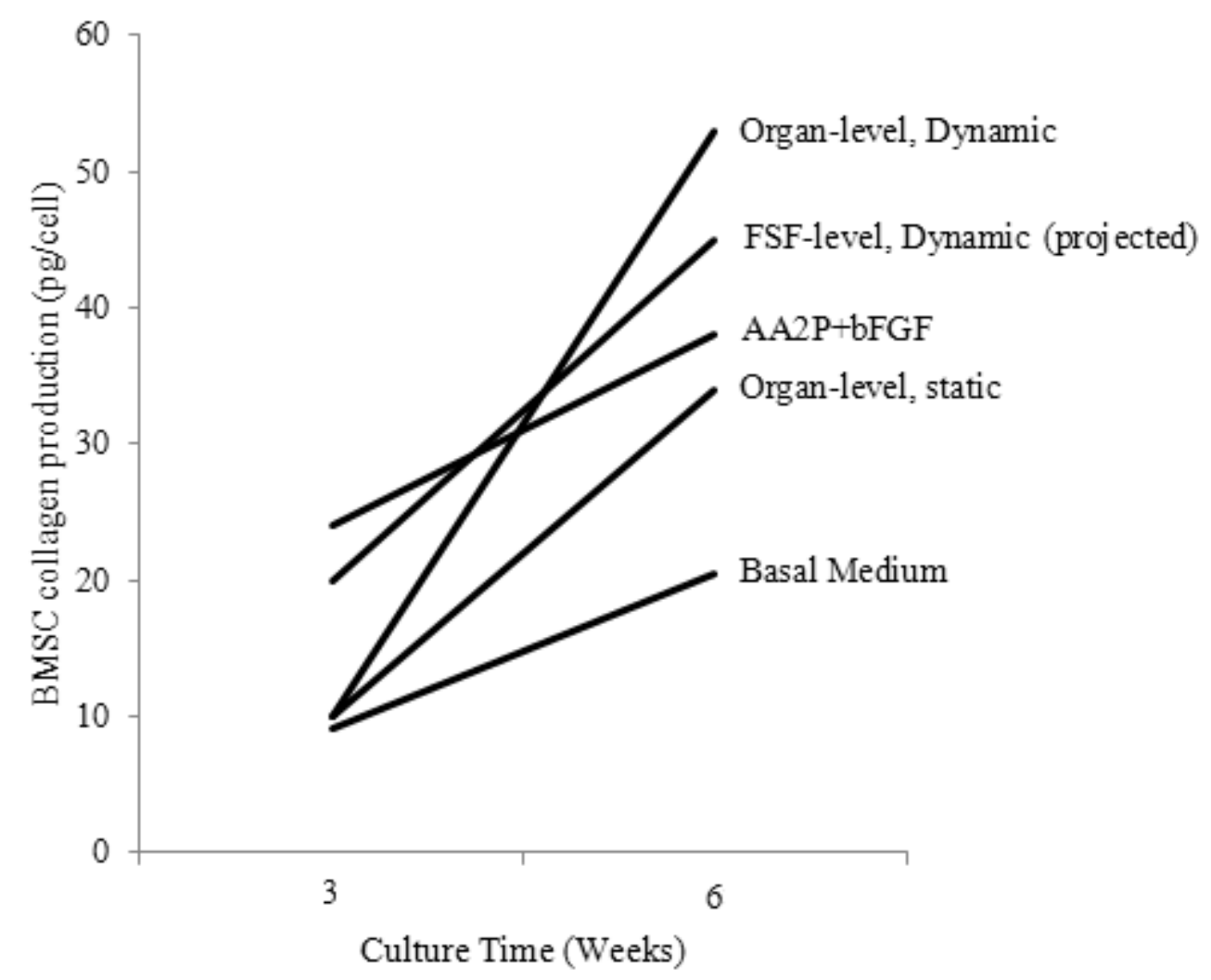

Figure 36. A compilation of the temporal evolution of collagen mass production for all groups investigated at the tissue and organ levels [7].

\section{CONCLUSION}

Through a computational modeling approach this study has shown that OSS can be maximized by inducing pulsatile flow over straight scaffolds. Specifically, these 
results have shown that in average OSS environments show higher magnitude and that there it is more homogeneously distributed along the sample walls. These findings demonstrate that experiments for HVTE that focus on OSS do not require a moving component. In this way, bioreactor designs could be further simplified to accommodate for pulsatility rather than movement by means of external actuators. It is our belief that OSS promotes BMSCs proliferation and tissue formation. The results of this study have shown that there is strong evidence to support this hypothesis. Current efforts are focused on in-vitro experiments that will provide with quantifiable data. 


\section{REFERENCES}

[1]Gandaglia A, Bagno A, Naso F, Spina M, Gerosa G. Cells, scaffolds and bioreactors for tissue-engineered heart valves: a journey from basic concepts to contemporary developmental innovations. Eur J Cardio-Thorac 2011;39(4):523-531.

[2]Schoen FJ. Evolving Concepts Of Cardiac Valve Dynamics The Continuum Of Development, Functional Structure, Pathobiology And Tissue Engineering. Circulation 2008;118(18):1864-1880.

[3]Kleinstreuer C editor. Biofluid dymamics: Principles and applications. ; 2006.

[4]Ratner BD, Huffman AS, Schoen FJ, Lemons JE. An introduction to materials in medicine. 2nd ed.

[5]Silverthorn U. Human Physiology an Integrated Approach. Michigan:

Pearson/Benjamin Cummings; 2005.

[6]Lorna S. Surgery for valve disease in young people - beyond morbidity and mortality. Int J Cardiol 2010 12/3;145(3):411-412.

[7]Ramaswamy S, Gottlieb D, Engelmayr Jr. GC, Aikawa E, Schmidt DE, Gaitan-Leon $\mathrm{DM}$, et al. The role of organ level conditioning on the promotion of engineered heart valve tissue development in-vitro using mesenchymal stem cells. Biomaterials 2010 2;31(6):1114-1125.

[8]Design and Evaluation of a New Flow-Stretch-Flexure Bioreactor for Mechanical Conditioning of Engineered Heart Valve Tissues in the Physiological Range. ; 2008; .

[9]Bernard I. Mitral stenosis still a concern in heart valve diseases. Archives of Cardiovascular Diseases 2008 10;101(10):597-599.

[10]Butcher JT, Mahler GJ, Hockaday LA. Aortic valve disease and treatment: The need for naturally engineered solutions. Adv Drug Deliv Rev 2011 4/30;63(4-5):242-268.

[11]Dal Pan F, Donzella G, Fucci C, Schreiber M. Structural effects of an innovative surgical technique to repair heart valve defects. J Biomech 2005 12;38(12):2460-2471.

[12]Frederick J. S. New frontiers in the pathology and therapy of heart valve disease: 2006 Society for Cardiovascular Pathology, Distinguished Achievement Award Lecture, United States-Canadian Academy of Pathology, Atlanta, GA, February 12, 2006. Cardiovascular Pathology 2006 10;15(5):271-279.

[13]Zilla P, Brink J, Human P, Bezuidenhout D. Prosthetic heart valves: Catering for the few. Biomaterials 2008 2;29(4):385-406. 
[14]Baig K, Punjabi P. Heart valve surgery. Surgery (Oxford) 2008 12;26(12):491-495.

[15]Neuenschwander S, P. Hoerstrup S. Heart valve tissue engineering. Transpl Immunol 2004 4;12(3-4):359-365.

[16]Sodian R, Hoerstrup SP, Sperling JS, Daebritz SH, Martin DP, Schoen FJ, et al. Tissue engineering of heart valves: in vitroexperience. Ann Thorac Surg 2000;70:140144.

[17] Mol A. Tissue engineering og heart valves: advances and current challenges. Expert Rev Med Devic 2009;6(3):259-275.

[18]Shahbudin H. R. Choice of Prosthetic Heart Valve in Adults: An Update. J Am Coll Cardiol 2010 6/1;55(22):2413-2426.

[19]Mohammadi H, Mequanint K. Prosthetic aortic heart valves: Modeling and design. Med Eng Phys 2011 3;33(2):131-147.

[20]Waterbolk TW, Hoendermis ES, den Hamer IJ, Ebels T. Pulmonary valve replacement with a mechanical prosthesis.: Promising results of 28 procedures in patients with congenital heart disease. European Journal of Cardio-Thoracic Surgery 2006 $7 ; 30(1): 28-32$.

[21]Westhoff-Bleck M, Girke S, Breymann T, Lotz J, Pertschy S, Tutarel O, et al. Pulmonary valve replacement in chronic pulmonary regurgitation in adults with congenital heart disease: Impact of preoperative QRS-duration and NT-proBNP levels on postoperative right ventricular function. Int J Cardiol 2011 9/15;151(3):303-306.

[22]Talwar S, Rajesh MR, Subramanian A, Saxena A, Kumar AS. Mitral valve repair in children with rheumatic heart disease. J Thorac Cardiovasc Surg 2005 4;129(4):875-879.

[23]Pravin M. S. Tricuspid and Pulmonary Valve Disease Evaluation and Management. Revista Española de Cardiología (English Edition) 2010;63(11):1349-1365.

[24]Siu SC, Silversides CK. Bicuspid Aortic Valve Disease. J Am Coll Cardiol 2010 6/22;55(25):2789-2800.

[25]Elkayam U, Bitar F. Valvular Heart Disease and Pregnancy: Part I: Native Valves. J Am Coll Cardiol 2005 7/19;46(2):223-230.

[26]Elkayam U, Bitar F. Valvular Heart Disease and Pregnancy: Part II: Prosthetic Valves. J Am Coll Cardiol 2005 8/2;46(3):403-410.

[27]Iyengar SS, Pontefract DE, Barlow CW. Heart valve surgery. Surgery (Oxford) 2004 6/1;22(6):135-138. 
[28]El-Hamamsy I, Chester AH, Yacoub MH. Cellular regulation of the structure and function of aortic valves. J Adv Res 2010 1;1(1):5-12.

[29]Sutherland FW, Perry TE, Yu Y, Sherwood MC, Rabkin E, Masuda Y, et al. From Stem Cells to Viable Autologous Semilunar Heart Valve. Circulation 2005(21):27832791.

[30]Neuenschwander S, P. Hoerstrup S. Heart valve tissue engineering. Transpl Immunol 2004 4;12(3-4):359-365.

[31]Siepe M, Akhyari P, Lichtenberg A, Schlensak C, Beyersdorf F. Stem cells used for cardiovascular tissue engineering. European Journal of Cardio-Thoracic Surgery 2008 $8 ; 34(2): 242-247$.

[32]Kadner A, Hoerstrup SP, Zund G, Eid K, Maurus C, Melnitchouk S, et al. A new source for cardiovascular tissue engineering: human bone marrow stromal cells.

European Journal of Cardio-Thoracic Surgery 2002 6;21(6):1055-1060.

[33]Leor J, Amsalem Y, Cohen S. Cells, scaffolds, and molecules for myocardial tissue engineering. Pharmacol Ther 2005 2;105(2):151-163.

[34]Schmidt D, Dijkman PE, Driessen-Mol A, Stenger R, Mariani C, Puolakka A, et al. Minimally-Invasive Implantation of Living Tissue Engineered Heart Valves: A Comprehensive Approach From Autologous Vascular Cells to Stem Cells. J Am Coll Cardiol 2010 8/3;56(6):510-520.

[35]Huang C.Y., Pelaez D., Dominguez-Bendala J., Garcia-Godoy F., Cheung H.S. Plasticity of stem cells derived from adult periodontal ligament. Regen Med 2009;4(6):809-821.

[36]Ramaswamy S, Gottlieb D, Engelmayr Jr. GC, Aikawa E, Schmidt DE, Gaitan-Leon $\mathrm{DM}$, et al. The role of organ level conditioning on the promotion of engineered heart valve tissue development in-vitro using mesenchymal stem cells. Biomaterials 2010 2;31(6):1114-1125.

[37]Perry TE, Kaushal S, Sutherland FWH, Guleserian KJ, Bischoff J, Sacks M, et al. Bone marrow as a cell source for tissue engineering heart valves. Ann Thorac Surg 2003 $3 ; 75(3): 761-767$.

[38]Engelmayr GC, Sales VL, Mayer JE, Sacks MS. Cyclic flexure and laminar flow synergistically accelerate mesenchymal stem cell-mediated engineered tissue formation: Implications for engineered heart valve tissues. Biomaterials 2006 12;27(36):6083-6095. 
[39]Stickler P, De Visscher G, Mesure L, Famaey N, Martin D, Campbell JH, et al. Cyclically stretching developing tissue in vivo enhances mechanical strength and organization of vascular grafts. Acta Biomaterialia 2010 7;6(7):2448-2456.

[40]Fong P, Shin'oka T, Lopez-Soler RI, Breuer C. The use of polymer based scaffolds in tissue-engineered heart valves. Prog Pediatr Cardiol 2006 3;21(2):193-199.

[41]Chen $\mathrm{G}, \mathrm{Wu} \mathrm{Q}$. The application of polyhydroxyalkanoates as tissue engineering materials. Biomaterials 2005 11;26(33):6565-6578.

[42]Lichtenberg A, Breymann T, Cebotari S, Haverich A. Cell seeded tissue engineered cardiac valves based on allograft and xenograft scaffolds. Prog Pediatr Cardiol 2006 $3 ; 21(2): 211-217$.

[43]Labrosse MR, Lobo K, Beller CJ. Structural analysis of the natural aortic valve in dynamics: From unpressurized to physiologically loaded. J Biomech ;In Press, Corrected Proof.

[44]Engelmayr GC, Rabkin E, Sutherland FW, Schoen FJ, Mayer JE, Sacks MS. The independent role of cyclic flexure in the early in vitro development of an engineered heart valve tissue. Biomaterials 2005;26(2):175-187.

[45]Engelmayr GC, Soletti L, Vigmostad SC, Budilarto SG, Federspiel WJ, Chandran KB, et al. A Novel Flex-Stretch-Flow Bioreactor for the Study of Engineered Heart Valve Tissue Mechanobiology. Ann Biomed Eng 2008;36(5):1-13.

[46]Hoerstrup SP, Sodian R, Sperling JS, Vacanti JP, Mayer JE. New Pulsatile Bioreactor for In Vitro Formation of Tissue Engineered Heart Valves. Tissue Eng 2000;6(1):75-79.

[47]Zeltinger J, Landeen LK, Alexander HG, Kidd ID, Sibanda B. Development and characterization of tissue-engineered aortic valves. Tissue Eng 2001;7(1):9-22.

[48]Lichtenberg A, Tudorache I, Cebotari S, Suprunov M, Tudorache G, Goerler H, et al. Preclinical testing of tissue-engineered heart valves re-endothelialized under simulated physiological conditions. Circulation 2006;114(1 Suppl):I559-565.

[49]Cebotari S, Lichtenberg A, Tudorache I, Mertsching H, Leyh R, Breymann T, et al. Clinical application of tissue engineered human heart valve using autologous progenitor cells. Circulation 2006;114(1 Suppl):132-137.

[50]Engelmayr GC, Hildebranda DK, Sutherland FW, Mayer JE, Sacksa MS. A novel bioreactor for the dynamic flexural stimulation of tissue engineered heart valve biomaterials. Biomaterials 2003;24(14):2523-2532. 
[51]Hildebrand DK, Wu ZJ, Mayer JE, Sacks MS. Design and Hydrodynamic Evaluation of a Novel Pulsatile Bioreactor for Biologically Active Heart Valves. Ann Biomed Eng 2004;32(8):1039-1049.

[52]Yeatts AB, Fisher JP. Bone tissue engineering bioreactors: Dynamic culture and the influence of shear stress. Bone 2011 2/1;48(2):171-181.

[53]Li YJ, Batra NN, You L, Meier SC, Coe IA, Yellowley CE, et al.

Oscillatory fluid flow affects human marrow stromal cell proliferation and differentiation. J Orthop Res 2004;22(6):1283-1289.

[54]Sales VL, Mettler BA, Engelmayr GC, Aikawa E, Bischoff J, Martin DP, et al. Endothelial Progenitor Cells as a Sole Source for Ex vivo Seeding of Tissue-engineered Heart Valves. Circulation 2010;16(1):257-267.

[55]Sacks MS, Yoganathan AP. Heart valve function: a biomechanical perspective. Phil Trans R Soc Lond Biol Sci 2007;362(1484):1369-1391.

[56]Evegren P, Fuchs L, Revstedt J. Wall shear stress variations in a 90-degree bifurcation in 3D pulsating flows. Med Eng Phys 2010 3;32(2):189-202.

[57]Evegren P, Revstedt J, Fuchs L. Pulsating flow and mass transfer in an asymmetric system of bifurcations. Comput Fluids 2011 10;49(1):46-61.

[58]Arnsdorf E, Tummala P, Kwon R, Jacobs C. Mechanically induced osteogenic differentiation - the role of RhoA, ROCKII and cytoskeletal dynamics. J Cell Sci 2009;122(Pt 4):546-553.

[59]Arnsdorf EJ, Tummala P, Jacobs CR. Non-Canonical Wnt Signaling and N-Cadherin Related b-

Catenin Signaling Play a Role in Mechanically Induced

Osteogenic Cell Fate. PLos One 2009;4(4):e5388.

[60]Lotz J, Meier C, Leppert A, Galanski M. Cardiovascular Flow Measurement with Phase Contrast MR Imaging: Basic Facts and Implementation. RadioGraphics 2002;22(3):651-671.

[61]He X, Ku DN. Pulsatile flow in the human left coronary artery bifurcation: average conditions. J Biomech Eng 1996;118(1):74-82.

[62]Jacobs CR, Yellowley CE, Davis BR, Zhou Z, Cimbala JM, Donahue HJ. Differential effect of steady versus oscillating flow on bone cells. 1998;31(11):969-976.

[63]Sacks MS, David Merryman W, Schmidt DE. On the biomechanics of heart valve function. J Biomech 2009 8/25;42(12):1804-1824. 